\title{
Strategic Interaction between General Practitioners and Specialists: Implications for Gatekeeping
}

\author{
Catherine Schaumans *
}

This version: February 2008

\begin{abstract}
We propose to estimate strategic interaction effects between general practitioners (GPs) and different specialist types to evaluate the viability threat for specialists associated to the introduction of a mandatory referral scheme. That is, we show that the specialists' loss of patientele when patients can only contact them after a GP referral has important consequences for the viability of the specialist types whose entry decisions are strategic substitutes in GPs entry decisions.

To estimate the strategic interaction effects, we model the entry decisions of different physician types as an equilibrium entry game of incomplete information and sequential decision making. This model permits identification of the nature of the strategic interaction effects as it does not rely on restrictive assumptions on the underlying payoff functions and allows for the strategic interaction effects to be asymmetric in sign. At the same time, the model remains computationally tractable and allows for sufficient firm heterogeneity.

Our findings for the Belgian physician markets, in which there is no gatekeeping, indicate that entry decisions of dermatologists and pediatricians are strategic substitutes in the entry decisions of GPs, whereas the presence of gynecologists, ophthalmologists and throat, nose and ear-specialists has a positive impact on GP payoffs of entry. Our results thus indicate that transition costs are likely upon the implementation of gatekeeping and that these costs are mainly associated to the viability of dermatologists and pediatricians.
\end{abstract}

Keywords: entry, strategic interaction, GPs, specialists, gatekeeping

JEL-codes: I11, L10

*KULeuven; catherine.schaumans@econ.kuleuven.be

I thank Hans Degryse, Geert Dhaene, Stijn Ferrari, Michael Mazzeo, Erik Schokkaert, Patrick Van Cayseele, Frank Verboven and seminar participants at various places for helpful comments. Furthermore, I am grateful to Dendrite International Belgium for data provision and to the Flemish Science Foundation for financial support (FWO, Grant G.0089.04). 


\section{Introduction}

In health systems with gatekeeping, patients can access secondary care only following a referral from their general practitioner (GP). ${ }^{1}$ Since the presence of a gatekeeper is believed to contribute to efficiency and cost containment, policy makers in countries without gatekeeping are increasingly interested in the adoption of a mandatory referral scheme. France for example introduced a system of non compulsory coordinated care pathways for patients in January 2005, which includes the introduction of a preferred GP scheme and a reduction in patients' freedom of choice through financial incentives (HealthPolicyMonitor). Belgium and Germany recently introduced price differences between referred specialist visits and self-referrals and financial incentives are given to register with a preferred GP. ${ }^{2}$

The introduction of (elements of) gatekeeping however changes the entire organization of health care provision and affects the market opportunities for health providers. As a mandatory referral scheme restricts access to specialists, secondary care remains only available for those patients that really require it. Whereas this explains the believed efficiency benefit, it also entails a possible loss in viability for the current body of specialists. That is, the specialists' patientele will drop to the extent that patients were using their free choice of health provider to consume secondary care while GP care would have sufficed (i.e. patients wrongly self-refer). As a result, the changing market opportunities can lead to a decrease in the number of specialists that is sustained in the market. The related transition costs are relevant for the policy debate on the introduction of gatekeeping. Amongst others, policy makers have to decide whether or not to maintain the entire body of specialists through financial mechanisms or to retrain a portion of them. ${ }^{3}$

Quantifying the extent to which different specialist types are likely to be threatened in their viability is however hard. Constructing a direct measure would require detailed patient-level or specialist-level data, with an objective measure of the necessity of secondary care. As this data is not available, this paper suggests studying the strategic interaction effects of specialist types on GP payoffs as a proxy of this threat. ${ }^{4}$

But the nature of the strategic interactions between general practitioners and specialists is a priori not clear. That is, there are arguments for both complementarity and substitutability of their services. On the one hand, GPs and specialists are intended to be complementary: the GP is trained to have a very broad

\footnotetext{
${ }^{1}$ To be more specific, gatekeeping is present in a health care system if the following three criteria are fulfilled: Enrolment of patients with a specified GP for a fixed period of time; payment for GPs is mainly by capitation per enrolled patient; and specialist care is usually only granted following referral by a GP (De Maeseneer et al 1999). This paper focuses on the mandatory referral scheme (element 3 ) in the discussion on gatekeeping.

${ }^{2}$ For the US, $70 \%$ of all Americans with health insurance were enrolled in some form of managed care plan (Gried 2000). Several of the HMOs also practice gatekeeping. Recently, however, some HMOs have relaxed the restrictions on access to specialists (Ferris et al 2001).

${ }^{3}$ Also, the network incentives for GPs and specialists will increase substantially, resulting in an additional change in market conduct and market structure.

${ }^{4}$ Throughout the paper, we assume that only GPs will be assigned as gatekeepers. Gynecologists and pediatricians are thus not allowed to act as the primary care doctor for certain population groups. A US study by Kirk et al (1998) indicates that only a minority of gynecologists identify themselves as primary care providers.
} 
knowledge on all current medical problems and can refer the more complicated and more care intensive cases to specialists, who are in turn better trained in specialized fields. GPs thus benefit from the presence of a specialist as they can refer when it would otherwise require a lot of effort to treat the patient. We refer to this as the referral effect. On the other hand, to some extent GPs and specialists deliver the same services, i.e. they diagnose patients and propose (and possibly perform) a treatment. Mainly when patients can choose freely among health providers, specialists are competing for patients with GPs. ${ }^{5}$ This is referred to as the competition effect. Whereas GPs benefit from the option to refer, they thus also risk that patients visit the specialist directly. This is especially detrimental for GPs when it concerns health problems GPs can treat at reasonable costs. With both effects present, it is not clear a priori whether the referral or the competition effect dominates the strategic interactions between GPs and different specialist types. Furthermore, this critically depends on the type of specialist and the regulatory framework in which health professionals are active.

We argue that specialist types whose presence currently has a negative impact on GP payoffs are most likely to experience viability problems upon the introduction of a mandatory referral scheme. That is, the negative effect indicates that the competition effect dominates the referral effect. Furthermore, it shows that many patients self-refer to specialists while often specialist care is not required. This is exactly the flow of patients that is excluded under a mandatory referral scheme.

To infer whether the competition or the referral effect dominates the strategic interaction of different specialist types with GPs, we model their entry decisions as a strategic game in the tradition of Bresnahan and Reiss (1991a) and Mazzeo (2002). The paper proposes the use of a sequential incomplete information game to answer the research question. These modeling assumptions avoid issues of non-existence of equilibria in case the strategic interaction effects are asymmetric in sign. They furthermore avoid restrictions on the underlying payoff function with respect to the effect of other-type firms, while allowing for sufficient firm heterogeneity. Contrary to most models in the literature, our model thus has the appropriate flexibility to identify the nature of the strategic interaction effects, while it remains computationally tractable. We apply the structural entry model to the Belgian physician markets, which are characterized by free choice of physician and a fee-for-service system. We simultaneously estimate the drivers of profitability and strategic interaction effects for GPs and different specialist types.

Our results indicate that specialist types benefit from the presence of GPs in the market. On the other hand, the effect of specialists on GP payoffs depends on the specialization field. Dermatologists and pediatri-

\footnotetext{
${ }^{5}$ Newhouse (1990): "In reality, however, there is a certain amount of competition among specialties; this is perhaps most apparent between a general (or family) practitioner, on the one hand, and a general internist (or general pediatrician) on the other hand, but almost all specialists perform some services or procedures that other specialists also perform." (p.211)
} 
cians have a negative impact on GP payoffs, while the entry decisions of gynecologists, ophthalmologists and throat, nose and ear-specialists (TNE) are strategic complements to the entry decision of GPs. No significant effect is found for psychiatrists and physiologists. Our findings therefore indicate that dermatologists and pediatricians attract a lot of patients for whom GP care would suffice, while the patientele of gynecologists, ophthalmologists and TNE-specialists either get referred or correctly self-refer to these specialist types. We thus expect considerable transition costs when gatekeeping would be introduced in the Belgian care system. Especially dermatologists and pediatricians are likely to experience a fall in the demand for their services, which can result in viability problems.

There is a large literature that evaluates the efficiency gains and the quality or budget effects of the presence of a gatekeeper in health care systems (Kulu-Glasgow et al 1998, Delnoij et al 2000, Gerdtham and Jönsson 2000, Ferris et al 2001, Brekke et al 2007). This paper deviates from the literature as we instead start from the observation that several European countries (e.g. Germany, France and Belgium) are currently introducing elements of gatekeeping. Policy makers seem to be convinced that the arguments in favor of gatekeeping outweigh the possible negative effects. Although we perform no welfare analysis, we want to increase awareness of the transition costs that accompany the change in the health care system due to changing market opportunities for health providers. Our analysis is furthermore related to the literature on managed care (Glied 2000) and physician behavior, such as on the referral practice of GPs (Marinoso and Jelovac 2003), on the degree of specialization in the care markets (Baumgardner 1988, Newhouse 1990) and on the competitive behavior between experts and non-experts (Bouckaert and Degryse 2000).

The methodology used in this paper contributes to the growing literature on equilibrium models of entry. Traditionally, the focus of modeling entry decisions of different firm types has been on questions of product differentiation: are firm payoffs affected to the same extent by the entry of other-type firms as they are by the entry of same-type firms? The literature provides a wide range of applications such as on the competition between airlines (Berry 1992, Ciliberto and Tamer 2004), between motels (Mazzeo 2002) and between banks (Cohen and Mazzeo 2007). There are only few examples that cover positive strategic interaction effects, i.e. strategic complementarity (Sweeting 2007, Schaumans and Verboven 2008). The current paper distinguishes itself from previous work as it is a priori not clear how the strategic interaction effects are characterized. As a result, we do not follow the common practice of making restrictive assumptions on the effect on payoffs of other-type firms to construct a well-defined likelihood function. That is, we do not restrict the strategic interaction effects to be negative or positive. Furthermore, we do not impose the interaction effects to be symmetric in sign. The latter is needed as we can not exclude that e.g. GPs are strategic complements for specialists' payoffs, while these specialists are strategic substitutes in the entry decision of GPs. 
The paper is organized as follows. We start in Section 2 by discussing the characteristics of the organization of health care markets in Belgium and issues of gatekeeping. We explain how identification of strategic interaction effects between physician types translates into the probability of viability issues upon the introduction of gatekeeping. Section 3 presents the entry model to determine the strategic interaction effects and discusses the particular strengths of the model given the research question. Section 4 follows with the data description and the empirical implementation of the equilibrium model to the Belgian physician markets. The results of the analyses are presented and discussed in Section 5 and Section 6 concludes.

\section{The Organization of Health care Markets}

Before introducing the equilibrium model of entry to identify strategic interaction effects between GPs and different specialist types, we briefly discuss the characteristics and the organization of the primary and secondary health care in Belgium. We focus on the entry requirements, the conduct and the interaction between physician types. We continue with some background on the literature on gatekeeping and focus on providing additional intuition on how the estimation of an entry model is of interest for the discussion on the introduction of mandatory referral schemes.

\subsection{The Belgian Health care Market}

The delivery of health care in Belgium is mainly private and based on the principles of independent medical practice. The Belgian health care market is characterized by a high physician density. For 2005, we account for the presence of one GP per 859 inhabitants. Furthermore, for a total population of about ten million there are close to 40,000 active physicians (GPs and specialists), which makes Belgium the second most physician dense country of Europe, after Greece (OECD Health Data). The high availability of medical care is also associated with a high consumption level of care services: Belgians on average have 4.6 contacts with a GP and 2.3 contacts with specialists per year.

Entry into the medical professions is conditional on minimum educational standards (licensing). First of all, because of the high physician density in Belgium, the government decided in 1998 to limit the inflow of professionals. This regulation is transposed in the Flemish region (North) to restrictions on the inflow of students for medical studies, whereas the Walloon region (South) opted for a limitation further in the educational cycle. All medical students start with a six-year program, which covers the basics for all physician types, followed by a one-year introduction to the preferred specialization, which mostly consists of internships. 
After this initial period of seven years, medical students start their study of a specialty to obtain a license to practise: such fields of specialization include e.g. general medicine, gynecology and dermatology. Again, there exists a restriction on the number of students that can start in each specialization field. These further studies consist of two years of internships and seminars for GPs and on average 5 years of study and internships for the different specialist types. It should be noted that retraining to another specialization field is very rare: also retraining from a specialist type to a GP requires additional study. Apart from these educational requirements and some administration, entry in the Belgian physician markets is free. That is, a certified and registered physician of any type can choose to locate an office anywhere in Belgium. ${ }^{6}$

Most GPs operate solo, frequently without any staff except perhaps a medical secretary. ${ }^{7}$ GPs typically perform a combination of open office hours, appointments and home visits. Furthermore, most GPs are enrolled in a local system of night and weekend duty to ensure availability of primary care at all times. Specialists are on the other hand often associated to hospitals. However, some fields of specializations do not necessarily require the hospital environment for their services, which results in a situation in which specialists have several offices: one within the hospital and a private practice. Depending on the type, patients therefore often visit specialists outside the hospital: this is especially the case for dermatologists, pediatricians, ophthalmologists and gynecologists (about $50 \%$ of all specialist visits). In this context, specialists typically perform consultations on appointment.

Both GPs and specialists are in general remunerated through fee-for-service payment where fee levels are set at the national level by the Convention Committee of the mutualities and physicians. As a result, a drop in workload directly translates into a decrease of income. The fee-for-service system furthermore prevents price competition amongst physicians of the same type. A consultation with a specialist is however substantially more expensive than a GP contact: in January 2005, patients' copayment for a consultation was $3.29 €$ with a GP, while the patient pays on average more than $10 €$ for a specialist contact. Although there is no price competition and furthermore self-regulation traditionally prevented physicians to compete through advertising, physicians do however have a wide range of other instruments they can use to compete with: quality of treatment, time spend on a consultation, availability, home visits (for GPs), waiting time and so on.

\footnotetext{
${ }^{6}$ This is in contrast to the regulation in some neighboring countries. In The Netherlands and Germany, there is regulation on the number of physicians per local market. Belgium has similar regulation for the pharmacy market. Adjustments to the entry model for these entry restrictions for the study of these markets are demonstrated in Schaumans and Verboven (2008).

${ }^{7} 75 \%$ of the population indicates visiting a GP that operates solo (WIV, 2006). The percentage of GPs working solo is expected to be a bit higher than this. Note that there are centers, known as integrated health care practices, which operate as a multidisciplinary team. The number of such practices is growing, although there is still only a small minority of people affiliated to them. Our dataset however does not allow us to identify them.
} 
The Belgian health care system does not include a gatekeeping role for GPs. Neither referral nor enrolment system is in place. There is free choice of physician and since the functions and roles of most health care personnel have not been clearly defined, specialists often form the first point of contact. Therefore, as discussed in the introduction, GPs benefit from the presence of specialists as they can refer to them, but at the same time their presence is a source of competition. Note that for specialists, referrals are likely to be less costly as the initial tests have already been performed and the health problem is very likely to match the specialist's expertise.

A study by WIV (2006) on the utilization of medical services in Belgium reports that about $6 \%$ of GP contacts end in a referral to a specialist. The bulk of specialist contacts concerns follow-ups: only $31 \%$ of specialist contacts are new, compared to $82 \%$ for GPs. Furthermore, about $55 \%$ of these new contacts occur on the patient's own initiative. However, there is a large difference according to the type of specialist: for contacts to dermatologists (gynecologists), patients initiate 68\% (67\%) of the contacts, whereas for internists or (neuro-) psychiatrists only resp. $41 \%$ and $26 \%$ of the contacts are self-referrals. The high frequency of selfreferred specialist contacts suggests that specialists are responsible for limiting the demand for GP services. We however have no indication on the character of the complaint and thus on whether or not a GP would be able to treat these patients. A study in the Netherlands, one of Belgium's neighboring countries, though indicates that patients self-refer for medical complaints for which they expect to end up at the specialist anyway and when the problem is considered to be specific for the specialist (Kulu-Glasgow et al, 1998). Remember that patients do have an incentive to contact a GP for general or minor health concerns, instead of a specialist because of the price difference.

Containment of health expenditure has been on the political agenda since the eighties and in 1993, some initiatives were launched to serve this purpose: amongst others there was a significant increase of copayment. But with the challenges of ageing and the development of expensive new medical techniques, initiatives on cost containment and efficiency remain important. In 1999, the Belgian authorities started with financial incentives for patients to participate in a system of enrolment with a preferred GP. Over the first five years, more than $30 \%$ of the population already enrolled. Moreover, in 2004, 95\% of the population indicates having a regular GP (WIV 2006) and a 2001-survey of one of the Belgian mutualities indicates that $75 \%$ of the patientele of a GP is loyal to his/her GP. ${ }^{8}$ This indicates that the majority of patients seem not to be 'shopping around' as far as GP care is concerned. Secondly, as of February 1st, 2007 a specialist contact that is not initiated by a GP referral has become more expensive for the patient, although the price difference of

\footnotetext{
${ }^{8}$ Loyalty is here defined as not having any contacts with any other GP throughout the year. (Socialistische Mutualiteit, 'Flits' Oktober 2001).
} 
$5 €$ is only valid for one visit per year. ${ }^{9}$ It is thus clear that initial steps towards a gatekeeping system are taken, while the debate on implementing a full gatekeeping system is still ongoing.

The characteristics of the Belgian health care markets motivate the modeling assumptions made in the entry model presented in section 3. First, because of the educational requirements in the physician markets, each firm knows its type before the entry game starts. Entrants therefore make no type choice. Furthermore, although licensing limits the total number of potential physician entrants, the lack of restrictions on the number of entrants in a local market implies that the pool of entrants for a specific local market is large. ${ }^{10}$ Second, since the majority of GPs still operate in a solo-practice and because data availability prevents identifying those physicians connected to a group or hospital, we treat all entry decisions as individual decisions. The presence of hospitals will however be an important indicator for the profitability of mainly specialist types.

\subsection{Gatekeeping}

Gatekeeping delegates the responsibility of the use of all secondary care to GPs through their referral behavior (Scott, 2000). As such, GPs are in charge of effectively and efficiently guiding patients through the health care system. The introduction of gatekeeping is therefore believed to make the use of secondary care more efficient. That is, an informed player (the GP) decides on the use of the expertise of specialists rather than patients, who are subject to uncertainty, asymmetric information and moral hazard (Arrow 1963). Furthermore, as the GP becomes the primary coordinator and communicator, the enhanced long run relationship can further increase efficiency as it allows taking the more general background of the patient into account. Gatekeeping is also believed to contribute to cost control, as it prevents wasteful duplication of diagnostic tests and unnecessary use of expensive secondary care (Franks et al 1992). These possible cost (quality) and efficiency gains of a gatekeeping role for GPs make legislators prone to implement it in their health system. ${ }^{11}$

Although the arguments in favor of gatekeeping seem convincing, there is actually little empirical evidence for the believed efficiency and cost benefits. For example, Barros (1998) and Delnoij et al (2000) both find

\footnotetext{
${ }^{9}$ De Artsenkrant, No. $87(31 / 01 / 2007)$. Note that because we are working on data prior to the introduction of the feedifferential related to a referral, the model is able to capture the way specialists and GPs interact in the absence of gatekeeping.

${ }^{10}$ To the extent that there are too few licensed physicians to cover the different geographic markets, the model changes in the constant term: the positive payoff condition to trigger entry is then replaced by the condition of payoffs higher than the best alternative. This is just a matter of normalization of the outside option.

${ }^{11}$ A bit simplified, more or less half of the Western-European countries do restrict access to secondary care by referral (UK, Spain, the Netherlands, Italy, Ireland, Denmark, Norway and Portugal), whereas the other half do not delegate this role to their GPs (Belgium, France, Germany, Sweden, Switzerland, Luxembourg, Greece and Austria). The United States is characterized by a mixed system, depending on the patient's choice of health insurance. Patients that are enrolled in an HMO are generally monitored by a gatekeeper, whereas patients that choose to sign in on a PPO have direct access to all care. However, several HMO's in the US are gradually opening up access to specialist care for their enrolled patients (e.g. Harvard Vanguard Medical Associates). Source: CESifo 2000 DICE, Boerma 2002.
} 
that the magnitude of health expenditure is not affected by the presence of a gatekeeping role. The only effect they can account for is a slower increase in the costs (for ambulatory care) in time. Ferris et al (2001) find little evidence of substantial changes in the use of specialty services by US HMO members in the first 18 months after abolishing gatekeeping and Nivel (2003) indicates that gatekeepers are in general not better informed about their patients. ${ }^{12}$ Brekke et al (2007) furthermore suggests that gatekeeping can be associated with overspecialization and excessive quality competition and survey results indicate a lack of support by patients and physicians for the introduction of gatekeeping. Also the danger of diagnostic delay is used as an argument against the introduction of gatekeeping.

An additional argument against the implementation of gatekeeping concerns costs related to altering an existing care system based on free choice towards a system with mandatory referrals. One such transition cost is directly related to the viability of the active professionals.

In a system with free choice, a patient can visit a specialist or a GP, irrespective of whether or not he/she requires specialist care. In case the patient needs specialist care, the GP will refer the patient to the appropriate specialist. The choice of directly contacting a specialist reduces transaction costs in case the patient would end up with this specialist type either way, but holds the risk of paying a higher fee than necessary (when one could have been treated by the GP) or the risk of delay or a wrong treatment (when the patient visits the wrong type of specialist). With the introduction of gatekeeping, the option of directly visiting the specialist is excluded. All patients visit the GP in a first instance and only those that need specialist care are redirected to the appropriate specialist type. This implies that specialists loose a part of their patientele: those patients that only need GP care will no longer end up in the specialist's office. In case specialists are paid according to a fee-for-service system, this drop in patientele directly affects their profitability. And to the extent that this flow of patients is important, the changing market opportunities due to the installment of a gatekeeper affect the viability of specialists and therefore reduces the total number of specialists that can operate in the market. This argument is in line with survey results from Germany where specialists indicate to fear financial losses due to gatekeeping (Gress et al 2004).

For insights on the likelihood of these viability issues for a specialist type, we rely on the strategic interaction effect of this type of specialists on the entry decision of GPs. This strategic interaction effect captures whether GP payoffs are increasing or rather decreasing in the number of specialists in the market.

\footnotetext{
${ }^{12}$ Evidence on the general health outcomes would be instructive in the discussion but is hard to come by. There is some indirect evidence that gatekeeping has a positive effect on health outcomes in Macinko et al (2003). Here it is shown that countries with a strong primary care system (Primary Care score test) are more successful in preventing mortality. Since countries with gatekeeping generally have a stronger primary care system, the positive relation might carry through (Gress et al, 2004).
} 
To facilitate the discussion, take for now that GP payoffs are given by variable profits minus fixed costs:

$$
\pi_{G P}=q \cdot S \cdot(p-m c)-F
$$

with $q$ the average number of patient's contacts with a GP, $S$ the total number of patients, $p$ the fixed fee, $m c$ the average marginal cost of a contact and $F$ the fixed costs. GP payoffs are affected in different ways by the presence of specialists. First, it allows GPs to refer complicated or care intensive cases which reduces the average marginal costs of treatment for the GP $(m c)$. In general, payoffs are thus higher when specialists are present in the market, due to the referral effect. ${ }^{13}$ Second though, patients can contact the specialist instead of the GP (competition effect). This implies a drop of the average number of contacts a patient has with the GP $(q)$. However, when patients self-select and only go to the specialist directly when they actually need specialist care, the drop in the number of contacts is associated with a drop in GP marginal costs. It is therefore especially when most patients wrongly diagnose themselves as in need of specialist care that GP payoffs will decrease due to the competition effect. That is, average marginal costs do not drop, while patients contact the GP less frequently.

When GP payoffs are increasing in the number of specialists of a certain type, the benefits of referrals outweigh the costs of competition (strategic complementarity). Patients that require the care of these specialists thus mainly access secondary care through the GP (high referral effect) and only few patients misdiagnose themselves in their self-referred visits to specialists (low competition effect). On the other hand, payoffs decreasing in the number of specialists of a type indicate that the competition effect dominates the referral effect (strategic substitutes). Patients access secondary care primarily through self-referral (or more precisely, GPs rarely need to refer patients to this specialist type), while many of them don't require specialist care (high competition effect).

Again, the introduction of a mandatory referral scheme excludes the possibility of patients to access secondary care directly. All patients that previously visited specialists while GP care would have sufficed will no longer be part of the specialist's patientele. Given the previous discussion, we know that this will especially threaten the viability of those specialist types that negatively affect GP payoffs. That is, for these specialist types, the loss of patientele will be substantial.

\footnotetext{
${ }^{13}$ Whereas the number of visits of these patients to the GP drops, the availability of the GP increases, which could counterbalance the drop in number of visits. That is, other patients visit the GP more frequently as the shadow price of care (=monetary+transportation costs+waiting costs) decreases.
} 


\section{$3 \quad$ Entry Model}

In this section, we present a static entry model to estimate the strategic interaction effects between specialist types and GPs. This allows us to determine whether the competition effect or the referral effect dominates the impact of specialist types on GP payoffs. In turn, this is instructive for the likelihood of viability threats for a specialist type once gatekeeping is introduced: the profitability of mainly specialist types whose entry decisions are strategic substitutes for the entry decision of GPs will be affected (section 2.2).

We propose to model the entry decisions of the different types of physicians as a sequential game of incomplete information with firm heterogeneity: firms have private information about their payoffs in a market and the types make their entry decisions in a pre-specified order. We start this section by introducing the model set up, firm behavior and the equilibrium of the game. This is followed by a discussion on the choice of the modeling assumptions: the model is especially designed to identify the signs of strategic interaction effects, while allowing for sufficient firm heterogeneity and asymmetric strategic interaction effects. We contrast our model mainly to models of complete information.

\subsection{The Empirical Model}

The empirical model to tackle our research question is closest related to the incomplete information game in Einav (2003). In a study to explain the observed demand patterns in the movie industry, Einav presents a sequential game of incomplete information to explain the timing decision of movie distributors. Each firm makes a zero/one decision for the 'entry' of the movie in a time horizon. Our model differs in two respects. First, in our setting firms make decisions to enter geographic markets. The unit of observation is therefore a local market as opposed to a point in time. Second and more importantly, the setting of Einav concerns few potential entrants with observable heterogeneity, for which he considers the timing decision separately. This paper on the other hand groups physicians into homogeneous types and looks at the aggregate decision of each physician type. We thus study the equilibrium number of entrants per type, which increases the dimensionality of the model. We subsequently present firm payoffs of entering the market and the assumptions of the game and discuss firm behavior and the conditions under which a market structure is the unique Bayesian Nash equilibrium.

\subsubsection{Set-up and payoffs}

Let the set of players in market $m$ be grouped in $T$ types, with $\mathcal{F}_{t}$ potential firms of type $t(t \in[1, T])$. The action space of all players consists of entering or not entering the market. Following the discussion in section 
2.1 (and as in Einav 2003), firms are considered to be individual decision makers and are not ex ante the same. ${ }^{14}$ Each firm knows its type before the entry game starts and all types have a large pool of potential entrants. We denote GPs as firms of type 1 and the different specialist types are assigned type 2 to type $T$. While payoffs of not entering the market are normalized to zero, we represent payoffs of a firm $f$ of type $t$ entering market $m$ by the following reduced form:

$$
\begin{aligned}
\pi_{f, t}^{m} & =\bar{\pi}_{t}\left(\mathbf{X}^{m}, n_{1}^{m}, \ldots, n_{t}^{m}\right)-\varepsilon_{f, t}^{m} \\
& =\beta_{t} \mathbf{X}^{m}+\alpha_{t} n_{t}^{m}+\sum_{\substack{j=1 \\
j \neq t}}^{T} \gamma_{t j} n_{j}^{m}-\varepsilon_{f, t}^{m}
\end{aligned}
$$

Firm payoffs depend on market characteristics $\left(\mathbf{X}^{m}\right.$, such as the number of inhabitants) and the entry decisions of other firms. Type-specific coefficients allow for the payoffs to vary across types. Furthermore, payoffs vary across (same-type) firms because of firm-specific characteristics. These firm-specific characteristics are assumed to be unobserved by both the researcher and other firms $\left(\varepsilon_{f, i}^{m}\right)$, although the distribution of the random variable of which the private information is a realization is known by all players. ${ }^{15}$ Since firms of the same type are therefore observationally the same, the exact identity of the entrants of a type is irrelevant for payoffs. Instead, payoffs are affected by the realized number of entrants of the different types in the market $\left(n_{1}^{m}, \ldots, n_{T}^{m}\right)$. Consistent with the existing literature, same-type firms are strategic substitutes, so that payoffs are decreasing in the number of firms of the own type: $\alpha_{t}<0 .{ }^{16}$ For the effect on payoffs of the number of entrants of other types, we make a simplifying assumption:

$$
\gamma_{t j}=0 \quad \forall t \neq 1, j \neq 1
$$

It is assumed that payoffs of all specialist types $(t \neq 1)$ are affected only by the number of own-type rivals and by the number of GPs in the market. In other words, the entry decisions of firms of different specialist types are independent from each other, at least in first order: there remain some indirect effects between specialist types through their simultaneous effect on the GP market. The restriction on the strategic interaction effects reduces the computational burden of the model to a considerable extent, so that it allows for the estimation

\footnotetext{
${ }^{14}$ This is in contrast with for example Mazzeo (2002), where firms make both an entry decision and a type decision. In his setting, all firms are ex ante homogenous.

${ }^{15}$ The firm-level error can be interpreted as both non-strategic considerations that make some players more likely to choose to enter this specific market or as an optimization error (Einav 2003).

${ }^{16}$ Note that we use this assumption in deriving the equilibrium behavior of the firms, but do not restrict the related coefficient in the estimation procedure. Instead, the data demonstrates this competitive effect.
} 
of a high degree of firm heterogeneity. Given the characteristics of the application, the assumption is not strong: specialists rarely refer patients directly to other specialist types. ${ }^{17,18}$ Note that GPs' payoffs (type 1) on the other hand are affected by the number of physicians of all types.

In contrast to most of the existing empirical literature, we make no assumptions on the signs of the strategic interaction effects. Instead, estimation of the model will yield insights on this. A negative effect $\left(\gamma_{t j}<0\right)$ indicates that the entry decisions of type- $j$ firms are strategic substitutes to the entry decision of firms of type $t$ : the entry of a type- $j$ firm in the market yields an additional competitive effect. A positive effect $\left(\gamma_{t j}>0\right)$ on the contrary implies strategic complementarity in the entry decisions for firms of type $t$ as payoffs of entering a market increase in the number of other-type firms. Furthermore, the strategic interaction effects between any two types of firms are allowed to be asymmetric, both in magnitude $\left(\gamma_{12} \neq \gamma_{21}\right)$ and in sign $\left(\gamma_{12}<0 \& \gamma_{21}>0\right)$. The latter is a particular strength of the model and worth elaborating on: for expositional reasons we delay the discussion to section 3.2. Remark that the current application cannot exclude the possibility of this asymmetry in sign: whereas specialists are expected to be positively affected by the entry decision of GPs, the competitive effect can dominate the strategic effect of a specialist type on GP payoffs.

With firms' payoffs of entering market $m$ at hand, we model their entry decisions as a strategic three-stage game: in the first stage, all potential entrants of type 1 simultaneously make their entry decisions. In the second stage, type-2 to type- $T$ players simultaneously decide on entry. When all potential entrants made their entry decisions, all firms that have entered market $m$ interact with each other and payoffs are realized.

Two remarks are in place. First, the assumption that GPs make their entry choices first is motivated by the consideration that a GP's patientele is mainly trust-based and very local whereas this is rather reputationbased in the specialists' markets. As such, GPs sunk costs of entering a specific local market and therefore their commitment power is higher. ${ }^{19}$ Second, because of the assumption on the strategic independence of specialists types, the simultaneous entry stage for all specialist types (stage 2) yields the exact same market equilibrium as a game in which the different types would enter sequentially in a pre-specified order: the second stage would then consist of $(T-1)$ stages (see Einav 2003).

\footnotetext{
${ }^{17}$ The restriction is more severe within the context of a hospital in which specialists do 'refer' to each other. As our dataset does not allow us to identify which specialists are associated to which hospital, we can however not control for this. The number of hospital beds will however be taken up as an explanatory variable in the estimation of the model, to partly control for this.

${ }^{18} \mathrm{In}$ case the application does not allow to make similar simplifying assumptions on the strategic interaction effects, the researcher has to go back to a $(T+1)$-stage game, in which a precise order is specified (see Einav 2003 for the consequences).

${ }^{19}$ This is in contrast with the general argument that material investments to enter a market as a specialist are higher. Note though that these costs are not market-specific. To the extent that specialists are mainly associated to hospitals, their sunk costs can be higher, which would justify a reverse order of play. The current sequence of entry decisions is however convenient as it reduces computational burden in the presence of more than two types. Finally, note that instead of making an assumption on the sequence of entry, Einav (2003) allows to estimate the likelihood of the different orders of play. This however requires that the dataset is very rich.
} 


\subsubsection{Firm behavior and Equilibrium}

As payoffs contain a private information component, firms make entry decisions based on their expected payoffs of entry. Each firm forms its expectation on payoffs using all observable information in the market and the private realization of its unobservables, together with a conjecture on the actions of all other firms. Note that the choice behavior depends only on the expected actions of other firms and not on the exact realizations of the unobservables of the other firms (as is the case in complete information games). Using this information, each firm decides whether or not to enter the local market $m$. Since firms are assumed to be rational payoffs maximizers, firms enter when they deem it to be profitable. Therefore, in the long run, the equilibrium market structure in market $m$ consists of the maximum number of firms that is viable, given their product differentiation.

Firms furthermore decide according to a pre-specified order of play: GPs (type 1) are the first-movers while the different specialist types simultaneously decide in the second stage of the game. As a result, the model can be solved backwardly for its perfect Bayesian equilibrium (Einav 2003).

\section{Second stage}

In the second stage of the game, type- 1 firms have already made their entry decisions and the $\mathcal{F}_{t}$ potential entrants of the other types $t(t \in[2, T])$ now simultaneously decide on entry in market $m$. They use all available information and thus condition their choice behavior on the observed number of type- 1 entrants $\left(N_{1}=n_{1}^{m}\right)$. Furthermore, the entry decisions are independent across type. Given the payoff specification in (1), firms of type 2 to type $T$ thus base their entry decision on the following conditional expected payoffs of entering market $m$ :

$$
\begin{aligned}
E\left(\pi_{f, t}^{m} \mid n_{1}^{m}\right) & =E\left(\bar{\pi}_{t}\left(\mathbf{X}^{m}, n_{1}^{m}, N_{t}\right)\right)-\varepsilon_{f, t}^{m} \\
& =\beta_{t} \mathbf{X}^{m}+\alpha_{t} E\left(N_{t} \mid n_{1}^{m}\right)+\gamma_{t 1} n_{1}^{m}-\varepsilon_{f, t}^{m}
\end{aligned}
$$

For notational convenience, we often refer to the deterministic part of these expected conditional payoffs as $E\left(\bar{\pi}_{t}^{m} \mid n_{1}^{m}\right)$.With all other determinants of payoffs observed, type- $t$ firms only conjecture on the choice behavior of their own-type rivals to form their expected payoffs. Each individual type- $t$ firm enters the market when its private information realization allows profitable entry, given the expected market structure: $E\left(\bar{\pi}_{t}^{m} \mid n_{1}^{m}\right) \geq \varepsilon_{f, t}^{m}$. 
As payoffs of all firms of the same type are observationally symmetric and the distribution of the private information is common knowledge $(G)$, all firms of type $t$ have in equilibrium the same conjecture on the number of entrants of its type in market $m$. That is, firm $f$ 's conjectured probability of a rival firm $g$ entering the market is the same as the probability of any other rival entering and also the same as the conjecture any rival has about the probability that firm $f$ enters: $\operatorname{Pr}_{f, t}\left(E\left(\bar{\pi}_{t}^{m} \mid n_{1}^{m}\right) \geq \varepsilon_{g, t}^{m}\right)=\operatorname{Pr}_{g, t}\left(E\left(\bar{\pi}_{t}^{m} \mid n_{1}^{m}\right) \geq \varepsilon_{f, t}^{m}\right)=$ $G\left(E\left(\bar{\pi}_{t}^{m} \mid n_{1}^{m}\right)\right) .{ }^{20}$ This also implies that the probability of being viable in a market with $\left(n_{1}^{m}, n_{t}^{m}\right)$ entrants is the same for all firms of type $t$. As a result, the probability that the equilibrium market structure consists of $n_{t}^{m}$ entrants of type $t$ coincides with the probability that a single firm is profitable (and thus enters) given this market structure but would not be profitable in the presence of an additional competitor (i.e. $n_{t}^{m}+1$ entrants). For any realization of the number of type-1 firms $\left(N_{1}=n_{1}^{m}\right)$, the probability that in the Nash equilibrium, $n_{t}$ firms of type $t(t \in[2, T])$ enter market $m$ can be written as: ${ }^{21}$

$$
\begin{aligned}
\operatorname{Pr}\left(N_{t}=n_{t}^{m} \mid n_{1}^{m}\right) & =\operatorname{Pr}\left(\bar{\pi}_{t}\left(\mathbf{X}^{m}, n_{t}^{m}, n_{1}^{m}\right) \geqslant \varepsilon_{f, t}^{m}>\bar{\pi}_{t}\left(\mathbf{X}^{m}, n_{t}^{m}+1, n_{1}^{m}\right)\right) \\
& =G\left(\bar{\pi}_{t}\left(\mathbf{X}^{m}, n_{t}^{m}, n_{1}^{m}\right)\right)-G\left(\bar{\pi}_{t}\left(\mathbf{X}^{m}, n_{t}^{m}+1, n_{1}^{m}\right)\right)
\end{aligned}
$$

\section{First stage}

Potential entrants of type 1 make their entry decisions first and decide based on their expected payoffs of entering market $m$. In contrast to the second movers, type-1 firms conjecture on the choice behavior of their own-type rivals and of the firms of all other types:

$$
\begin{aligned}
E\left(\pi_{f, 1}^{m}\right) & =E\left(\bar{\pi}_{1}\left(\mathbf{X}^{m}, N_{1}, N_{2}, \ldots, N_{T}\right)-\varepsilon_{f, 1}^{m}\right. \\
& =\beta_{1} \mathbf{X}^{m}+\alpha_{1} E\left(N_{1}\right)+\sum_{\substack{j=1 \\
j \neq t}}^{T} \gamma_{1 j} E\left(N_{t}\right)-\varepsilon_{f, 1}^{m}
\end{aligned}
$$

The potential entrants however anticipate on the choice behavior of type- $t$ firms: their decision rules are deduced from their equilibrium behavior in the second stage of the game as given in expression (3). Note

\footnotetext{
${ }^{20}$ In the presence of firm-specific characteristics, type- $t$ firms can be considered as heterogeneous and not only the number but also the identity of the entrants becomes relevant for payoffs. Expectations can then differ across firms (Seim 2007).

${ }^{21}$ Remark that we get the same probability of observing a market structure as in the case where the error term is the same for and observed by all type- $t$ physicians (only!). This is due to the symmetry assumption.
} 
that the decision rules of the type- 2 to type- $T$ firms depend on the realization of the number of entrants of type 1 so that the expectation of the number of other-type firms depends directly on the expectation of the number of same-type rivals. The expected number of firms of type 2 to type $T$ in market $m$ in the payoffs of type-1 firms $\left(E\left(N_{t}\right)\right.$ in expression 4$)$ can thus be updated by integrating out over the probability of observing $n_{t}^{m}$ specialists of type $t$ entering the market, conditional on the number of type- 1 firms:

$$
E\left(N_{t}\right)=\sum_{n_{t}^{m} \in \mathcal{F}_{t}} \operatorname{Pr}\left(N_{t}=n_{t}^{m} \mid E\left(N_{1}\right)\right) \cdot n_{t}^{m} \quad \forall t \neq 1
$$

As a result, the expected payoffs can be written to only depend on the expectation of the number of entrants of the own type $\left(E\left(\bar{\pi}_{1}\left(\mathbf{X}^{m}, N_{1}, N_{2}, \ldots, N_{T}\right)=E\left(\bar{\pi}_{1}\left(\mathbf{X}^{m}, N_{1}\right)\right)\right.\right.$. The symmetry of the payoffs of type-1 firms and the common knowledge of the distribution of the private information component implies that all GPs form the same equilibrium conjecture on the number of entrants. Furthermore, individual rational behavior yields conditions for the equilibrium number of type-1 firms entering the market. That is, the probability that a market structure with $n_{1}^{m}$ firms of type 1 is a Nash equilibrium, is given by the probability of a type- 1 firm being profitable in the presence of $n_{1}^{m}$ rivals, but unprofitable with an additional entrant in the market:

$$
\begin{aligned}
\operatorname{Pr}\left(N_{1}=n_{1}^{m}\right) & =\operatorname{Pr}\left(E\left(\bar{\pi}_{1}\left(\mathbf{X}^{m}, n_{1}^{m}\right)\right) \geqslant \varepsilon_{f, 1}^{m}>E\left(\bar{\pi}_{1}\left(\mathbf{X}^{m}, n_{1}^{m}+1\right)\right)\right) \\
& =G\left(E\left(\bar{\pi}_{1}\left(\mathbf{X}^{m}, n_{1}^{m}\right)\right)\right)-G\left(E\left(\bar{\pi}_{t}\left(\mathbf{X}^{m}, n_{1}^{m}+1\right)\right)\right)
\end{aligned}
$$

\section{Perfect Bayesian Nash Equilibrium}

From the second stage of the game, we derive the equilibrium behavior of all firms of type 2 to type $T$ (i.e. of all specialist types) conditional on the number of entrants of type 1 . In the first stage of the game, we deduced the equilibrium number of type-1 entrants that realizes taking into account the reactions of the other types to these entry decisions. In sum, the assumption of rational firm behavior yields a probability of observing a number of firms of any type in the market (equations (3) and (6)). Combining both stages, the probability of observing market structure $\left(n_{1}, n_{2}, \ldots, n_{T}\right)$ in market $m$ is described by:

$$
\begin{aligned}
\operatorname{Pr} \quad\left(N_{1}=\right. & \left.n_{1}^{m}, N_{2}=n_{2}^{m}, \ldots, N_{T}=n_{T}^{m}\right) \\
& =\operatorname{Pr}\left(N_{1}=n_{1}^{m}\right) \cdot \operatorname{Pr}\left(N_{2}=n_{2}^{m} \mid n_{1}^{m}\right) \cdot \ldots \cdot \operatorname{Pr}\left(N_{T}=n_{T}^{m} \mid n_{1}^{m}\right)
\end{aligned}
$$


Given a specification of the reduced form payoff function for firm types and an assumption on the distribution of the private information, the estimation proceeds through the maximization of a likelihood function, where every market is treated as an independent game. With $n_{t}^{m^{*}}$ the observed number of entrants of type $t$ in market $m$, the likelihood function is given by:

$$
L\left(\beta_{t}, \alpha_{t}, \gamma_{t j}\right)=\prod_{m=1}^{M} \operatorname{Pr}\left(N_{1}=n_{1}^{m^{*}}, N_{2}=n_{2}^{m^{*}}, \ldots, N_{T}=n_{T}^{m^{*}}\right)
$$

\subsection{Discussion}

The entry model put forward in section 3.1 is one of incomplete information and firms deciding in a prespecified order. These modeling assumptions are used explicitly to meet the requirements of the research question at hand:

1. We intend to identify the sign of the strategic interaction effects between different physician types.

2. We cannot exclude the possibility that the strategic interaction effects between GPs and a specialist type are asymmetric in sign. That is, GPs' payoffs might decrease in the number of a specialist type, while this specialist type benefits from the presence of GPs in the market.

3. There exists a lot of different types of physicians: GPs, dermatologists, pediatricians, gynecologists, psychiatrists, and so on. We thus want to allow for sufficient firm heterogeneity (at least more than two firm-types).

The bulk of the literature considers games of complete information: all characteristics of payoffs are common knowledge for the firms, including the realization of the error terms. Therefore, the action of every firm depends not only on the realization of its own unobservables, but also on the realization of the unobservables of the other potential entrants. We use a graphical representation of the entry game to show that when the information set is complete, the probability of observing a market structure critically depends on the nature of the strategic interaction effects. Figure 1 represents the empirical model with two types and one potential entrant for each type under complete information and simultaneous decision making for three cases: (A) the interactions between firms is given by strategic substitutability (payoffs of entry decrease in the entry of the other type), (B) strategic complementarity in the entry decisions of both firms (firms benefit from the presence of the other type firm) and (C) the strategic interaction effects are asymmetric in sign. 
The $\mathrm{X}$-axis represents realizations of the unobservables of the firm of type 1 , whereas the $\mathrm{Y}$-axis gives the realizations of the unobservables of the type-2 firm. The broken lines represent threshold values for entry: if the realization of the own error term lies below this threshold value, rational firm behavior prescribes firms to enter the market (e.g. $\left.\bar{\pi}_{1}\left(\mathbf{X}^{m}, 1, N_{2}\right) \geq \varepsilon_{1}^{m}\right)$. As this entry decision depends on the realization of the error of the other-type firm, each firm has two threshold values, one for the entry decision when the firm is the only entrant $\left(n_{-i}^{m}=0\right)$ and one for the entry decision when the other firm is present in the market $\left(n_{-i}^{m}=1\right)$. Given the threshold values of both firms, we can associate equilibrium market structures to error term realizations. The areas associated with equilibrium market structures $\left(n_{1}^{m}, n_{2}^{m}\right)$ are depicted on the graphs.

The problem with complete information games should be clear directly: while we aim to identify the nature of the strategic interaction effects, the probability associated to a market structure depends on the assumption made on the strategic interaction effects. ${ }^{22}$ In other words, when the researcher want to take a complete information game to the data, defining the likelihood function implies making an assumption on the nature of the strategic interaction effects. It is straightforward that we do not want to make such assumptions. Moving towards a setting of incomplete information avoids this: firms make their entry decisions based on their expected payoffs, which consists of a conjecture of the likelihood of entry of the other firm given observable information on the other firm's payoffs. Firms use this conjecture to determine its entry decision: the firm will enter in case expected payoffs are positive (e.g. $\left.E\left(\bar{\pi}_{1}\left(\mathbf{X}^{m}, 1, N_{2}^{m}\right)\right) \geq \varepsilon_{f, 1}^{m}\right)$. Figure 2 gives the graphical representation of the empirical game under incomplete information and simultaneous decision making. Importantly, the same mapping results for the three possible cases of strategic interactions between firms. That is, as opposed to the complete information game, each firm only has one threshold value due to the independence of its entry decision of the realization of the error term of the other-type firm. The strategic interactions between firms however determine the level of these threshold values.

The second requirement of the empirical application is the fact that the strategic interactions need to be flexible. In a setting of complete information and pure equilibrium strategies, a game with strategic interactions that are asymmetric in sign suffers from issues of non-existence of an equilibrium for certain realizations of the model primitives. In case one firm is harmed by the presence of the other, while the other firm benefits from the presence of the first, as depicted in panel $\mathrm{C}$ of Figure 1, it is possible that any strategy by the players has a profitable deviation by at least one of them. ${ }^{23}$ For such realizations of the

\footnotetext{
${ }^{22}$ Look back at Figure 1, assuming without loss of generality that firm 1 moves first (to solve for the multiplicity issue). The equilibrium mapping for market structure $(0,1)$ is a rectangle in the strategic complementarity case, whereas it takes a different form under the assumption that the entry decisions are strategic substitutes.

${ }^{23}$ The firm of type 1 is willing to enter the market if it can be alone in the market. But in case the type- 1 firm enters, it is optimal for the type-2 firm to enter as well since its entry is profitable given this market structure. However, in the latter case, the type-1 firm would not be profitable.
} 
model primitives no equilibrium exists, so that no well-defined likelihood function can be specified. Models of complete information therefore do not only require the strategic interactions to be known a priori, but also that the strategic interaction effects between two types have the same sign. When in contrast firms decide based on expectations of the actions of the other players, as in Figure 2, an equilibrium exists for all realizations of the model primitives. Note though that while an equilibrium always exists, the incompleteness of the information set gives rise to ex-post regret. That is, once the entry decisions of the other players become clear, the firm's decision to (not) enter might not have been the optimal one. Remark furthermore that an alternative solution to the non-existence problem in the complete information game consists of allowing for mixed-strategy equilibria (Bajari et al 2007, Aradillas-Lopez 2007).

Whereas an equilibrium always exists in the incomplete information game, the issue of multiple equilibria remains. For the same model primitives, the equilibrium conjecture on the behavior of other firms might not be unique (Berry and Reiss 2006). Most of the empirical work on incomplete information games constrains the shape of the payoff function or assumes that the same equilibrium is chosen in similar markets to solve for multiplicity concerns (Seim 2007, Aradillas-Lopez 2007, Vitorino 2007). ${ }^{24}$ However, as in games of complete information, the assumption of sequentiality results in unique equilibria as well: the second mover conditions its choice on the action of the first mover, so that the first mover can perfectly anticipate his choice behavior. Given the sequentiality assumption, only the first mover is subject to ex-post regret (Einav 2003). For the current application, we work with the sequentiality assumption to solve for the unique Bayesian Nash equilibrium. For completeness, we add the graphical representation of this model with the firm of type 1 as the first mover in Figure 3, where panel A and panel B respectively present the case in which the firm of type 1 is a strategic substitute or a strategic complement in the entry decision of the type- 2 firm. ${ }^{25}$

Finally, allowing for a high degree of firm heterogeneity is less demanding in an incomplete information setting (Seim 2007). Within the complete information framework, specifying the conditions for which a specific market structure with e.g. three firm-types is the equilibrium is complex: it results in complicated regions of integration. Recent developments in the literature however do allow for estimating a higher degree of firm heterogeneity in this setting, but reduces identification to the set of models for which the data is consistent (e.g. Ciliberto and Tamer $2004^{26}$ ). Instead, an incomplete information setting retains point

\footnotetext{
${ }^{24}$ Sweeting (2007) is an exception as this paper uses the multiplicity of equilibria explicitly in the identification strategy.

${ }^{25}$ Note that the specification of this model is invariant to the nature of the strategic interaction effect: the relevant threshold values for any market structure to be an equilibrium is the same in both panels.

${ }^{26}$ Ciliberto and Tamer (2004) does more than just dealing with the multiplicity concerns: they also allow for a flexible estimation of the underlying payoffs through giving up on point identification of the model. This method implies that the data itself will be used to determine how the areas of error term realizations connected to a certain market structure are defined. Computational burden however increases fast when the binary model is extended to estimating the number of firms of a type entering the market. Furthermore, although type specific variables and exclusion restrictions are not per se needed, they help reduce the bounds of the parameter set. Finally, an extension of the model is needed to allow for mixed equilibria when the strategic interaction effects do not have the same sign. Apart from these technical drawbacks in the empirical implementation,
} 
identification while being less computationally intensive.

Related to this computational burden, we decrease the complexity of the equilibrium and therefore the computation time further by assuming strategic independence between the different specialist types. In his timing game, Einav (2003) demonstrates the development of an equilibrium market structure in case there is strategic dependence between all types. That is, in a $(T+1)$-game where the order of play is clearly determined, all but the last mover anticipate on the behavior of some types and all but the first mover condition their expectations on other firms' choices. Finally, as indicated by Einav (2003) the equilibrium calculus is linear in the number of players in the market, and thus has the benefit over simultaneous incomplete information games, which rely on numerical search algorithms.

In sum, the modeling assumptions made are specifically required by the nature of the research question at hand. ${ }^{27}$ First, the specification of the empirical model is invariant to the nature of the strategic interaction effects and thus makes no related assumptions on the underlying payoff function. Second, it allows for asymmetric strategic interaction effects in GP-specialist interactions, as it avoids related issues of nonexistence of equilibria. Furthermore, we can model and estimate the entry decisions of multiple types of firms simultaneously while retaining point identification.

\section{Empirical Implementation}

To use the empirical entry model to explain the characteristics of the Belgian primary and secondary care markets, it remains to specify the reduced form payoff functions for the physician types and to make an assumption on the distribution of firm level unobservables. We start the empirical implementation section by introducing the data on the Belgian health care markets after which we discuss further implementation and identification issues.

\subsection{Data on Belgian health care markets}

In this section, we present the dataset for the study on Belgian GPs and specialists. The first step in the application of the entry model to Belgian physician markets consists of defining the relevant geographic market.

this methodology however does allow for a flexible estimation of the strategic interactions and correlation in the unobservables.

${ }^{27}$ A recent working paper by Vitorino (2007) addresses a related issue using a simultaneous game of incomplete information. She studies the presence of agglomeration effects of shopping centers and also uses the property of the incomplete information game of allowing for the effect of same type stores to be either positive (agglomeration dominates) or negative.(competition dominates). The setting is quite different though. She considers a limited number of potential entrants (3) with firm-specific characteristics of a limited number of potential types (3) to choose to enter a shopping mall. Note that there is a different interpretation of the concept of 'same-type effects' as in the current paper (Vitorino's types are comparable to our classes of specialists). Instead of assuming sequential entry, it is assumed that the same equilibrium is picked in similar markets. As a result, her estimation approach is more complex to solve for the equilibrium. 
There is however little guidance on this: unlike in the US, antitrust has not addressed any cases of merging physician offices, because this phenomenon is marginal in Belgium and prices are fixed. We nonetheless know that physicians cannot engage in advertising or other promotional selling activities. Therefore, patient choice is largely guided by local information. Furthermore, $95 \%$ of the Belgian population indicates having a regular GP which is conveniently located close to their home. The town might thus be as far as the sphere of influence for a GP reaches. For specialists on the other hand, it is generally believed that patients are willing to travel further, making the relevant geographic market of specialists larger (Ettinger 1998).

Belgium is made up of towns that are grouped into 586 municipalities, where the average municipality counts 17,590 inhabitants. In this paper, we define the municipality as relevant geographic market for all physician types. ${ }^{28}$ Allowing for differences in relevant market definition is subject of future research. For the empirical implementation of the model, we drop the big cities ( $>100,000$ inhabitants) from the dataset and concentrate on markets with at least one physician (of any type) active. This reduces the dataset to 576 Belgian municipalities.

\section{Health providers}

Privacy concerns limit the data availability on health care professionals to a location measure (= zip code). For general practitioners, we rely on a dataset of the Belgian Institute for Sickness and Invalidity Insurance (RIZIV/INAMI). From this dataset, we deduce the number of GPs that are truly active and available to the public (outside of hospitals). The selection of active and available GPs is based on their performance. As selection criterion we use a recent regulation (July 1st, 2006) which states that GPs will only remain certified if they have more than 500 visits in one of the last five years. From dialogue with RIZIV/INAMI, we add the restriction that GPs should have at least 50 patients in one of the last five years. ${ }^{29}$ We used data on the number of visits of all registered GPs from 2000 until 2004 to deduce the number of active GPs in the beginning of 2005. This procedure results in the identification of 11,842 GPs. These GPs have on average 3, 794.27 contacts per year (s.d. 3,464) and each serves on average 591.55 patients (s.d. 408). ${ }^{30}$

For specialists, a dataset from Dendrite Belgium gives the number of active specialists in Belgian zip codes according to their self-reported field of specialization in April 2005. ${ }^{31}$ We opt to work with every

\footnotetext{
${ }^{28}$ The relevant geographic market of a GP can be smaller than this, whereas the relevant geographic market of some specialist types can be larger. Working on an intermediate level (municipality) seems to be a good compromise. This definition is also in line with the empirical work on physicians in for example Baumgardner (1988) that works on US county level and Newhouse (1990) that uses the US towns as market definition.

${ }^{29}$ The basic selection rule corrects for non-specialists uniquely associated to a company and retired GPs that still treat their own family. As they are not open to the public, their impact on other GPs or specialists can be assumed away. The limitation with respect to the number of patients aims to filter out those GPs that only perform guard duty. They are excluded as they do not work within the same time frame as the genuine GPs, so that they cannot be considered genuine competitors.

${ }^{30} \mathrm{An}$ official report of RIZIV/INAMI $(03 / 07)$ indicates the presence of 11,799 active GPs in 2005 . We do not have the appropriate data to simulate their criteria exactly, although we are pretty close.

${ }^{31}$ There can be some difference between the official field of specialization, by their RIZIV-number or by the hospital they might work for, and the self-reported field of expertise. We choose to work with the self-reported fields as they probably capture
} 
location where a specialist is active. That is, we are not able to distinguish between the locations in terms of the time a specialist spends at certain offices. However, even if the specialist is only active in a local market for a small time period, he/she will still be available to patients and can thus be considered to interact with other health care providers. ${ }^{32}$ We furthermore aggregate specialties as to come to a manageable and more or less homogenous group of specialist types and define three classes of specialists. First, there are those who are claiming a role in the first line care (WIV 2006). In this class, we identify dermatologists (der), gynecologists (gyn), pediatricians (ped) and ophthalmologists (opht). The second class of specialists are in principle concerned with second or third line care, but often have a private office outside the hospital. This class consists of psychiatrists (psych), throat, nose and ear-specialists (TNE) and physiotherapists (phys). ${ }^{33}$ A third class of medical specialists is especially active in hospitals. Whereas internists (int) and surgeons (sur) are also available for private consultations, there is no direct access to the remainder of the specialists. We consider them as one group which we name the 'hospital specialists' (hos). Our focus lies on the first and second class of specialists.

A count of the Belgian physicians according to their type in the sampled municipalities is presented in the first column of Table 1. We identify for example 776 dermatologist and 1,431 gynecologist offices in Belgium. The average number of physicians per type on municipality level is given in the second column of the table. There are on average 17 GPs active in the selected municipalities, with a large variance: the dataset consists of both markets with only 1 GP and with more than 100 active GPs. The average number of specialists lies a lot lower at between 1 and 3 specialists of each type per market. Many municipalities lack specific specialists: on average $57 \%$ of all municipalities does not hold a specialist type. This is especially the case for markets that do not have a hospital: for these $74 \%$ of the markets, there are on average only 0.7 specialists of a specific type active. Note though that only $19 \%$ of all municipalities have no specialist of any type. It is also clear from the data that there is a strong positive correlation between the numbers of physicians of each type in a market. For example, the number of GPs has the highest correlation with the number of dermatologists, with a correlation coefficient of 0.85 and the correlation between specialist types averages around $86 \%$.

the specialists' activities best. Furthermore, we do not use the field of 'general medicine', as it overlaps with the GP dataset. Note finally, that the RIZIV/INAMI dataset could not be used for specialists, as the home address is reported instead of the working address.

${ }^{32}$ An alternative is to work based on the preferred address of the specialist. We believe that this understates the availability of specialists as well as the effect its presence has on other physicians in the same markets. We furthermore restrict the sample of specialists to those who have finished their degree completely. In other words, we do not take up assistants, which however do treat people. As they are always connected to a specialist, we regard the entire work staff of the specialist as one. The presence of assistants however helps to justify the use of all the working addresses of specialists.

${ }^{33}$ Note that some of the specialist groups we use, are a groups of different specialists. For example, physiotherapists comprise both the specialists in sports health and in physiotherapy. 


\section{Market characteristics}

To control for demand and cost characteristics in the different municipalities and for differences in the value of the outside option, we add a dataset with market characteristics for which the descriptive statistics are presented in Table 2. According to studies on health status and morbidity, the age, gender and ethnicity composition together with the socio-economic status of the service population are important indicators for the demand of GP care (Boerma, 2003). We have information from the National Institute of Statistics (NIS) on the number of inhabitants (pop, in thousands) and the population density (dens). The dataset moreover includes variables indicating the age composition of the local population. We opt to work with seven age groups; 'age0_4' gives the percentage population under the age of 5, 'age5_14', 'age15_29', 'age30_44', 'age45_59' and 'age60_75' give the percentage population in the respective age groups and finally 'age $75+$ ' gives the percentage elderly, defined as over the age of 75 . Further market characteristics are the percentage female population (female), the mean income level measured in ten thousand euros (income), the unemployment rate (unempl) and the percentage of foreign population (foreign).

We also add other sources of health supply that can have an effect on the profitability of physicians. We control for the number of hospital beds in the municipality (beds_hosp) and the number of beds in retirement homes (beds_rest). Finally, we have dummy variables indicating in which of the 11 provinces/regions of Belgium the market is located, to identify common profitability shocks (or value of the outside option) across municipalities in the same area. Note already that our conclusions on the strategic interaction effects between physician types are robust against different grouping of age categories and against the use of region dummies and alternative measures related to hospitals.

\subsection{Model implementation and Identification}

We use the payoff specification as introduced in equation (1) in which both the market characteristics and the number of firms enter linearly (for computational reasons). Note that this implies that we assume that an extra entrant always has the same impact on payoffs, irrespective of the number of entrants that is already present in the market. ${ }^{34}$ We allow for asymmetries both in magnitude and in sign, in the strategic interaction effects by estimating type-specific coefficients. Standard t-tests suffice to infer the nature of strategic interactions between Belgian physicians of different types. The market characteristics control for the demand of medical care and for the inherent profitability of the local market: we use the market characteristics discussed above in the analysis (section 4.1). Note that we use the age category $5-14$ and

\footnotetext{
${ }^{34}$ Theoretically, one can estimate a more realistic pattern of effects, with e.g. fixed effects for all market structures. However, our dataset restricts the extent to which we can identify such parameters: we have few markets with a low number of GP entrants and a lot of markets with no specialist entrants. Our assumption furthermore contains the number of parameters to estimate.
} 
the region of Brussels as the baseline and that we have no exclusion restrictions: all market characteristics can affect the payoffs of all physician types.

We treat the model unobservables $\left(\varepsilon_{f, t}^{m}\right)$ as realizations of a standard logistic distribution. Using this distributional assumption of the private information component of payoffs, we can specify the probabilities of observing $n_{t}^{m}$ physicians of type $t$, defined in equations (3) and (6), as ordered logit expressions: ${ }^{35}$

$$
\left\{\begin{array}{l}
t=1: \quad \operatorname{Pr}\left(N_{1}=n_{1}^{m}\right)=\frac{\exp \left(E\left(\bar{\pi}_{1}\left(\mathbf{X}^{m}, n_{1}^{m}\right)\right)\right)}{1+\exp \left(E\left(\bar{\pi}_{1}\left(\mathbf{X}^{m}, n_{1}^{m}\right)\right)\right)}-\frac{\exp \left(E\left(\bar{\pi}_{1}\left(\mathbf{X}^{m}, n_{1}^{m}\right)\right)\right)}{1+\exp \left(E\left(\bar{\pi}_{1}\left(\mathbf{X}^{m}, n_{1}^{m}\right)\right)\right)} \\
t \neq 1: \quad \operatorname{Pr}\left(N_{t}=n_{t}^{m} \mid N_{1}\right)=\frac{\exp \left(\bar{\pi}_{t}\left(\mathbf{X}^{m}, n_{t}^{m}, N_{1}\right)\right)}{1+\exp \left(\bar{\pi}_{t}\left(\mathbf{X}^{m}, n_{t}^{m}, N_{1}\right)\right)}-\frac{\exp \left(\bar{\pi}_{t}\left(\mathbf{X}^{m}, n_{t}^{m}, N_{1}\right)\right)}{1+\exp \left(\bar{\pi}_{t}\left(\mathbf{X}^{m}, n_{t}^{m}, N_{1}\right)\right)}
\end{array}\right.
$$

These probabilities are used directly to form the likelihood function as specified in equation (7). Remark that GPs decide based on expected payoffs, where they anticipate the choice behavior of the different specialist types. Calculating these expected payoffs therefore implies computing the probability of observing any number of specialists of any type conditional on any possible number of GP entrants (equation 5). ${ }^{36}$ For estimation, we reduce the dimensionality of the problem by limiting the number of physicians of each type to a maximum of $30\left(\forall t: \mathcal{F}_{t}=30\right)$. With $87.5 \%$ of our markets containing less than 30 GPs and virtually all municipalities having less than 30 specialists of a specific type, this assumption is not restrictive.

Estimation of the model identifies the coefficients related to the market characteristics $\left(\beta_{t}\right)$ and the coefficients related to the number of firms of own type and of the other types $\left(\alpha_{t}, \gamma_{t j}\right)$. All these coefficients are identified up to the scale of the error term. Furthermore, the effects of the other-type firms are not separately identified from possible correlation in the unobservables. The current framework does not allow for correlation in the realizations of the error terms. ${ }^{37}$ Consequently, the finding of a positive (negative) interaction effect can be due to real complementarities (substitutability) between the professionals, but can also originate from a positive (negative) correlation in the market unobservables. ${ }^{38}$ We follow two approaches to limit the related concerns: first, we correct for a lot of market characteristics, as to reduce the magnitude

\footnotetext{
${ }^{35}$ We can also estimate the model under the assumption that the unobservables are distributed according to a standard normal. This yields ordered probit expressions and our conclusions are robust against the distributional assumption.

${ }^{36}$ Note that the computational benefit of assuming GPs to move first lies here. In case the different specialist types were to decide first, each of them would have to anticipate on the choice behavior of the GPs, which condition on the entry decisions of all specialist types. As a result, one specialist type now has to take into account the choice behavior of all other specialist types.

${ }^{37}$ Note that models of complete information in general do not alleviate this problem: whereas they do allow for correlation in strategic interaction effects, separate identification of the correlation coefficient from these effects is not straightforward and requires good instrumentation in the payoffs of all types (Athey \& Stern, 2003).

${ }^{38}$ Also note that the assumption implies no correlation between the unobservables of the same firm in two markets and no correlation between the unobservables of two same type firms in the same markets. Complete information models on the other hand assume there to be perfect correlation within type - the error term realization is market and type specific but not firm specific. The reality probably lies in between.
} 
of the unobservables and second, we estimate the model while allowing for a high degree of firm heterogeneity in the market, which reduces the possible bias on the individual interaction effects in the GP payoff function.

Ideally, we would estimate a specification with a payoff function for all physician types separately. However, despite the reduction of computational burden due to the assumption of strategic independence between specialist types, we are still confronted with optimization problems (we have no exclusion restrictions). We therefore use the classes of specialists to reduce the number of firm types in the empirical model (see section 4.1). With our primary interest in the effect on GP payoffs of specialists of classes 1 and 2 , we estimate the model twice. In the first estimation, we focus on the strategic interaction of the entry decisions of GPs and specialist types of class 1, while grouping the other specialist types by class. That is, we specify payoffs for seven physician types: GPs, dermatologists, gynecologists, pediatricians, ophthalmologists, class-2 specialists and class-3 specialists. The second estimation does the same but then considers the specialist types of class 2. Payoffs are defined for six types: GPs, psychiatrists, TNE-specialists, physiologists, class-1 specialists and class-3 specialists. Note that the entry behavior of class-3 specialists is always included as an endogenous control variable in the identification of the strategic interaction effects of the other specialists. ${ }^{39}$ Our conclusions seem to be robust against alternative groupings of specialist types.

\section{$5 \quad$ Estimation Results and discussion}

Tables 3 and 5 present the results of the estimation of the empirical entry model in which we focus on the first class of specialists, for the strategic interaction effects and the market characteristics respectively. The estimated coefficients for the specification with class- 2 specialists are given in Tables 4 and 6 . The different columns of the tables give the estimated coefficients for the different physician types of the simultaneous estimation.

As a goodness-of-fit measure, we simulate the number of entrants of all types given the market characteristics. That is, for 1,000 random draws for the error terms (from a logistic distribution), we calculate the equilibrium number of entrants in each market. We are able to predict the number of entrants rather accurate: the observed number of entrants of all types always lies within the confidence bounds of the mean of our simulated number of entrants per market. Following Berry and Waldfogel (1999), we compute the correlation of the predicted and the actual number of entrants per type to construct a $\mathrm{R}^{2}$ for the regression. For the estimation with the class-1 (class-2) specialist types, we get an average $\mathrm{R}^{2}$ of $0.82(0.84) .{ }^{40}$

\footnotetext{
${ }^{39}$ Remark that we make the simplifying assumption that all specialist types of the same class are homogeneous. This implies that the entry of e.g. an internist has the same impact on internists' payoffs as the entry of a surgeon does. As we are not primarily interested in this group, we allow for this stringent assumption to lighten further computational burden.

${ }^{40}$ Note that the estimation with the focus on the class-2 specialists yields a very high predictive power for GPs with a type-
} 
First, consider the estimated coefficients for the strategic interaction effects in Tables 3 and 4 . The estimation results indicate that the effect of the number of firms of the own type is always negative. The higher the number of same-type rivals, the lower payoffs of entering the market. This is both consistent with economic theory and required by the equilibrium model we put forward. For the effect of the number of firms of the other types, the results are mixed. First, the number of GPs in the market positively affects payoffs of all specialist types (insignificant for physiologists). This can be explained by the lower workload of referred visits compared to self-referrals. That is, when a patient is referred by a GP, basic tests have been performed and the specialist can directly target the established health issues. A self-referral in contrast requires the specialist to spend more time and to perform more tests before he can pin down the real issue.

The strategic interaction effects in the GP payoff function on the other hand have varying signs. GP payoffs are positively affected by the number of gynecologists, ophthalmologists and TNE-specialists in the market. In other words, the benefits for GPs from the ability to refer outweigh the costs associated with the free access to these specialist types. Patients that require the care of these specialists thus mainly access secondary care through the GP (high referral effect) or correctly self-refer (low competition effect). The number of dermatologists and pediatricians however has a negative impact on GP probability of entry. The costs due to the competition for patients here outweigh the referral benefits. A high proportion of the patients that use these types of secondary care services thus visit specialists without a referral while not necessarily requiring it (high competition effect). Finally, we find no significant effect of the presence of psychiatrists and physiologists on GP payoffs. For Belgium, we can thus conclude that the use of gynecologists', ophthalmologists' and TNE-specialists' services can be considered as complementary to GP services, whereas the use of dermatologists' and pediatricians' services are mainly substitutes to GP services.

The results from the Belgian health survey (WIV 2006) can help explain this grouping. This survey indicates pediatricians and dermatologists as the two specialist types that generate the lowest percentage of follow-up contacts (62\% and $56 \%$ respectively). Therefore, a large part of their income depends on the new visits for which they can compete with GPs. The survey also identifies these specialist types as attracting the highest percentage of patients that self-refer $(73 \%$ and $68 \%)$. For gynecologists and ophthalmologist on the other hand, the survey indicates that the percentage of follow-up contacts is high $(82 \%$ and $73 \%)$, which implies fewer incentives to compete directly with GPs.

To illustrate the meaning of the magnitudes of the estimated strategic interaction effects, we simulate the predicted change in the number of GP entrants due to changes in the number of a specialist type under the current behavior of patients, GPs and specialists (not shown). The results of such simulation are especially

specific $\mathrm{R}^{2}$ of 0.93 . The estimation with the class- 1 specialists does worse in predicting the number of GP entrants $\left(\mathrm{R}^{2}=0.67\right)$, but the predictive power for the specialist types remains accurate. 
relevant in the direction of the change that they indicate and no so much in the magnitude of this change. ${ }^{41}$ For 1,000 random draws for the error terms (from a logistic distribution), we calculate the equilibrium number of GP entrants in each market given 0, 1, 2 or 3 specialists of a type, holding market characteristics and the observed number of entrants of other types constant. ${ }^{42}$ For dermatologists (pediatricians), we find that the equilibrium number of GP entrants decreases in the presence of more of these specialists. More specifically, the average market sustains 15.85 (15.15) GPs in the absence of dermatologists (pediatricians), while this decreases to an average of 8.24 (9.46) GPs when there is 1 of these specialists present in all markets and to 4.80 (6.06) GPs when every market holds 3 dermatologists (pediatricians). For e.g. gynecologists (TNE-specialists) the predictions go in the opposite direction as GPs benefit from the presence of these specialist types. Whereas the average market sustains 5.14 (10.28) GPs in the absence of gynecologists (TNE-specialists), the average number of GPs increases (non significantly) to 18.73 (14.68) when there is 1 of these specialists present in all markets and to 24.31 (23.12) GPs when every market holds 3 gynecologists (TNE-specialists).

The findings on the nature of the strategic interaction effects have further relevance for policy makers. When a mandatory referral scheme would be introduced in Belgium (or in case the price difference between referrals and self-referrals for specialist visits are sufficient to induce a comparable change in behavior by patients), the market opportunities of all health professionals change. The main effect of this is to be expected for dermatologists and pediatricians. That is, these specialist types now realize a substantial part of their business (income) from unnecessary self-referrals. Since this patient flow gets diverted to GPs upon the introduction of gatekeeping, substantial drops in patientele are likely. Since patients that use gynecologist, ophthalmologist and TNE-care mainly get referred to specialists or correctly self-refer, the main source of profitability is expected to remain intact for these health professionals.

An important remark is in place. In the analysis, we estimate the net effect of the presence of specialist types on GP payoffs. Therefore, the finding of a positive effect only implies that the referral effect dominates the competition effect. It can thus be the case that the competition effect is very big, but that the referral effect is slightly more important. In this case of course, a substantial impact of the introduction of gatekeeping is to be expected as well. That is, still a large proportion of the patientele (and the income) of the specialist

\footnotetext{
${ }^{41}$ We assume in the estimation that the effects of the number of firms of any type is linear. This implies that the effect of the first specialist-entrant has the same impact on GP payoffs as the entry of the third entrant of the same type. This might not be entirely realistic, but reduces the computational burden in the estimation to a significant extent. Also, we assume the behavior of all players to be constant over the different scenarios: obviously this is a strong assumption. Put differently, in a small market with e.g. 1 GP we simulate the impact on his profitability of entry of an entry by various numbers of specialist entrants, even though this could not realize in reality as the population size does not allow for any specialist to enter.

${ }^{42}$ Note first that the status-quo prediction of the average number of GPs in a market is rather accurate for the estimation of the class-2 specialists: in the presence of the observed number of entrants of all types, the average equals 13.28 , with the observed average, after we reduce the maximum number of entrants per market to 30 for estimation, equals 14.49. The average number of GP entrants per market under the observed number of specialists in the estimation on the class- 1 specialist types does worse with 7.67 , but a large standard deviation.
} 
type results from wrong self-referrals. Whereas dermatologists and pediatricians are expected to experience the largest drop in market demand, the other specialist types will also be affected to some extent by the introduction of mandatory referral schemes. We thus identify the 'lower bound' of the effect.

Consider for completeness the estimation results of the effects of market characteristics on the entry probabilities of the physician types in Tables 5 and 6 . Caution is to be advised in the interpretation of these results: our controls for market demand, costs and outside option are aggregate and exhibit a strong colinearity. In general though, we find that GP payoffs of entering a market are positively affected by population size. The bigger the potential market, the more profitable and thus probable is entry of a GP. Some less significant effects are found for the income level of the population and the presence of hospitals (only in one of the specifications). The finding of the positive effect of mean income level is unexpected. That is, most studies find a negative impact: a lower income also indicates a lower health status and mostly a lower use of specialist care. Also the positive impact of the number of hospital beds might be surprising as emergency rooms of hospitals are often used as an alternative for GP care in the weekend or at night (although the regulator tries to limit this). Note though that we also control for the number of specialists in these hospitals, which makes a clean interpretation hard. Other demographic characteristics seem not to matter for GP payoffs, once the presence of specialist types is accounted for.

The effects of market characteristics show similar patterns for the different specialist types. Market size (population) and the presence and size of hospitals are important indicators for the profitability of any specialist: the higher the number of inhabitants (except for psychiatrists) and the higher the number of hospital beds, the higher the probability of observing more specialists of any type. For most types, the age structure of the population also has an effect. With the baseline the percentage of kids $(5-14)$, the percentage of toddlers $(0-4)$ and the percentage population in the $45-59$ age category lower the payoffs of entry of (gynecologists), pediatricians and ophtamologists. On the other hand, entry payoffs of most specialist types are positively affected by the percentage population in the $15-29$ age group. The results seem not to be very intuitive in all cases, but should be taken into context. Consider e.g. pediatrician payoffs is negatively affected by the percentage toddlers. The estimation controls for a lot of other characteristics of the market. Therefore, this coefficient has the interpretation of the residual effect of the percentage toddlers, conditioned on e.g. the percentage of females in the market and conditional on the percentage of young adults. As expected, the percentage females and the mean income level positively affect the payoffs of especially the class- 1 specialists. The unemployment rate of the population negatively affects especially pediatricians. Finally, the province/region dummies are all estimated negatively, which can indicate a low value of the outside option for health professionals in the Brussels region. These dummies are however not 
significant for the GP and for class-3 specialists.

\section{Conclusion}

This paper investigates the nature of the strategic interactions between general practitioners and specialists of different types. More precisely, we study whether GPs benefit from the presence of a specialist due to the option of referral, or that rather the competition effect a GP experiences from specialists dominates their interaction. The entry literature lends itself nicely for studying health care markets, as data availability is often an issue. We put forward a sequential incomplete information entry game that has the flexibility to identify the sign of the strategic interaction effects between different types of firms. The model is designed to avoid restrictions on the underlying payoff functions with respect to the effect of other-type firms and to avoid issues of non-existence of equilibria in case the strategic interaction effects are asymmetric in sign. At the same time, the model remains computationally tractable and allows for sufficient firm heterogeneity. We use this game to study the strategic interactions in the Belgian physician markets, in which there is no gatekeeping role for GPs.

Whereas the entry literature has traditionally focused on questions of product differentiation, this paper demonstrates the use of entry models to tackle a different type of research question. That is, we study the precise nature of the strategic interactions between different types of firms. Although the entry literature has boomed in the last five years, not much attention has been given to this problem. Because of the tradition of studying problems of product differentiation, the assumption of types being strategic substitutes in the entry decision is ubiquitous. Often the strategic interactions between types of firms are however not this simple: even though the competition effect is most obvious, at least some positive effect from the presence of other-type firms are likely (think of e.g. agglomeration effects, Vitorino 2007). When modeling the strategic interactions between types of firms, it is therefore advisable to allow for the possibility that this positive effect is present and possibly dominates the negative effect. To model and estimate firm conduct while allowing for these more flexible interactions between firm types requires the researcher to abandon either the pure strategy equilibrium assumption or the assumption of complete information, with the latter strategy demonstrated in this paper.

For the Belgian physician markets, the results indicate that we can group specialists into three categories. First, the decisions of certain specialist types are strategic complements to the entry decision of GPs. This category includes gynecologists, ophthalmologists and throat, nose and ear-specialists (TNE). As GP payoffs 
are increasing in the number of specialists of these types, we find that the competition effect (patients go to the specialist instead of to the GP) is dominated by the referral effect (GPs' cost of treatment drop). Patients are especially referred to these specialist types or correctly self-refer to them. A second group of specialists consists of dermatologists and pediatricians, whose entry decisions are found to be strategic substitutes in the entry decision of GPs. These specialist types especially compete for patients with GPs. Self-referred visits make up a significant part of the income of these specialists and often concern health issues that do not require specialist care. The availability of a third group of specialist services has no significant impact on GP payoffs. That is, the positive referral effect balances out against the negative competition effect for psychiatrists and physiologists. On the other hand, specialists of all types benefit from the presence of GPs in the market.

As there is no gatekeeping in Belgium, the sign of the strategic interaction effects of specialist types on GPs' entry decisions is furthermore instructive for the likelihood of viability threats upon the introduction of gatekeeping into the care system. As the mandatory referral scheme excludes the possibility for patients to self-refer to a specialist, our findings suggest that mainly dermatologists and pediatricians are likely to be threatened in their viability with the introduction of gatekeeping. This is especially the case when gatekeeping is gradually introduced as in the case in Belgium and neighboring countries. That is, in case a mandatory referral scheme is implemented without the accompanying capitation system, the income level of specialists is directly affected. Furthermore, because of this, specialists have incentives to (start to) induce more demand for their services as to maintain their income level. The anticipated benefits in terms of cost containment would then not realize. Remark that data from RIZIV/INAMI on the number of contacts per GP for 2000-2004 indicates that the average workload of GPs has dropped over this time period: the average GP used to have 4, 025.25 contacts per year (s.d. 2, 587), whereas this average dropped to $3,794.27$ contacts per year in 2004 (s.d. 3, 464). The drop in the average contacts per year goes hand in hand with a drop in the average GP income level. We therefore expect that in a first reaction to the introduction of a mandatory referral scheme, GPs will experience the opportunity to restore their income level (in the current fee-for-service system). GPs will therefore have no incentives to redirect as many patients as possible to specialized care, so that the realization of substantial income drops for certain types of specialists is likely, at least in the medium run.

In case the mandatory referral scheme is combined with a capitation system, comparable problems emerge. To ensure viability, the fixed fee per patient enrolled with a specialist will have to be set high, both in absolute terms and compared to the capitation for the GP, as the number of patients per specialist will be relatively low. From a budget perspective, this will not be maintainable. In case the regulator puts a more realistic 
fixed fee for specialists, a proportion of the health professionals will experience viability problems and the transition costs will materialize. Note that the only way viability issues would not emerge is when GPs do not get the correct incentives. That is, in case GPs minimize their effort level and always refer patients to specialists, the current body of specialists can be sustained.

\section{References}

AFENDULIS C.C. and KESSLER D.P. Tradeoffs from integrating diagnosis and treatment in markets for health care. NBER Working Paper No 12623, 2006.

ARADILLAS-LOPEZ A. Semiparametric Estimation of a Simultaneous Game with Incomplete Information. Working Paper, Princeton University, 2007.

ARROW, K.J. "Uncertainty and the welfare economics of medical care." American Economic Review, 53 (1963), pp. 941-973.

ATHEY S.and STERN S. An Empirical Framework for Testing Theories about Complementarity in Organizational Design. NBER Working Paper no. 6600, 2003.

BAJARI P., HONG H. and RYAN S. Identification and Estimation of a Discrete Game of Complete Information. Working Paper, 2007.

BAJARI P., HONG H., KRAINER J. and NEKIPELOV D. Estimating Static Models of Strategic Interactions. Working Paper, 2007.

BARROS P.P. "The black-box of health care expenditure growth determinants". Health Economics, Vol 7 (1998), pp 533-544.

BAUMGARDNER J.R "Physicians' Services and the Division of Labor Across Local Markets". The Journal of Political Economy, Vol. 96 (1988), pp 948-982.

BERRY S.T. "Estimation of a Model of Entry in the Airline Industry." Econometrica, Vol. 60 (1992), pp. 889-917.

BERRY S.T. and REISS S. "Empirical Models of Entry and Market Structure". for Handbook of Industrial Organization, Vol. III, 2006.

BERRY S.T. and WALDFOGEL J. "Free entry and social inefficiency in radio broadcasting." RAND Journal of Economics, Vol 30 (1999), pp. 397-420.

BOUCKAERT J. and DEGRYSE H. Price competition between an expert and a non-expert. International Journal of Industrial Organization Vol 18 (2000), pp. 901-923.

BREKKE K.R., NUSCHELER R. and STRAUME O.R. "Gatekeeping in health care". Journal of Health Economics, Vol 26 (2007), pp. 149-170.

BRESNAHAN T.F. and REISS P.C. "Entry and Competition in Concentrated Markets." Journal of Political Economy, Vol. 99 (1991a), pp. 977-1009.

BRESNAHAN T.F. and REISS P.C. "Empirical Models of Discrete Games." Journal of Econometrics, Vol. 48 (1991b), pp. 57-81.

CILIBERTO F. and TAMER E. Market Structure and Equilibria in Airline Markets. Working paper, Northwestern University, 2004.

COHEN A. and MAZZEO M. Investment Strategies and Market Structure: An Empirical Analysis of Bank Branching Decisions. Working Paper, 2007.

DE MAESENEER J., BOGAERT K., DE PRINS L. and GROENEWEGEN P. "A literature review". In: Brown S, eds., Physician funding and health care systems - an international perspective, The Royal College of General Practitioners, London, pp 17-32, 1999. 
DELNOIJ D., VAN MERODE G., PAULUS A. and GROENEWEGEN P. "Does general practisioner gatekeeping curb health care expenditure?", Journal of Health Services Research and Policy, Vol. 5 (2000), pp. 22-26.

ETTINGER D. JD "The truth about antitrust". Family Practice Management, Vol. 5 (1998).

EINAV L. Not All rivals Look Alike: Estimating an Equilibrium Model of The Release Date Timing Game. Working Paper, 2003.

FERRIS T.G., CHANG Y., BLUMENTHAL D. and PEARSON S.D. "Leaving gatekeeping behind - Effects of opening access to specialists for adults in a Health Maintenance Organization". New England Journal Of Medicine, Vol 345 (2001), pp. 1312-1317.

FRANKS, P., CLANCY C.M. and NUTTING P.A. "Gatekeeping revisited - protecting patients from overtreatment", New England Journal of Medicine, Vol 327 (1992), pp.424-429.

GERDTHAM U-G. and JöNSSON B. "International Comparisons of Health Expenditure: Theory, Data and Econometric Analysis". In: A.J. Culyer and J.P. Newhouse, eds., Handbook of Health Economics Vol. 1, Chapter 1, 2000.

GRESS S., HESSEL F., SCHULZE S. and WASEM J. "Prospects of gatekeeping in German social health insurance", Journal of Public Health, Vol 12 (2004), pp. 250-258.

GLIED S. "Managed Care." In: A.J. Culyer and J.P. Newhouse, eds., Handbook of Health Economics Vol. 1, Chapter 13, 2000.

KIRK E.P., SANTA J., HECKLER T. and COLLINS, M. "Obstetrician-gynecologists as primary care physicians: The Oregon experience-Early perceptions regarding the effects of legislative action", American Journal of Obstetrics \&3 Gynecology, Vol 178 (1998), pp 1222-1228.

KULU-GLASGOW I., DELNOIJ D. and DE BAKKER D. "Self-referral in a gatekeeping system: patients'reasons for skipping the general-practitioner". Health Policy, Vol. 45 (1998), pp 221238

MARINOSO B.G. and JELOVAC I. "GPs' payment contracts and their referral practice". Journal of Health Economics, Vol. 22 (2003), pp. 617-635.

MAZZEO M.J. "Product Choice and Oligopoly Market Structure." RAND Journal of Economics, Vol 33 (2002), pp. 221-242.

NEWHOUSE J.P "Geographic Access to Physician Services". Annual Review of Public Health, Vol 11 (1990), pp 207-230.

NIVEL "Eurocommunication II; A comparative study between countries in Central- and WesternEurope on doctor-patient communication in general practice". Nivel, 2003.

SCHAUMANS C. and VERBOVEN F. "Entry and regulation - evidence from health care professions". RAND Journal of Economics, forthcoming.

SCOTT A. "Economics of General Practice". In: A.J. Culyer and J.P. Newhouse, eds., Handbook of Health Economics Vol. 1, Chapter 22, 2000.

SEIM K. "An Empirical Model of Firm Entry with Endogenous Product-Type Choices." RAND Journal of Economics, Vol. 37 (2006), pp. 619-640.

SWEETING A. Coordination Games, Multiple Equilibria and the Timing of Radio Commercials. Working Paper, Department of Economics, Duke University, 2007.

VITORINO M.A. Empirical Entry Games with Complementarities: An Application to the Shopping Center Industry, Working Paper, Graduate School of Business, University of Chicago, 2007.

WETENSCHAPPELIJK INSTITUUT VOLKSGEZONDHEID (WIV). "Gezondheidsenquête door middel van Interview, België, 2004." Nationaal Instituut voor de Statistiek, IPH/EPI REPORTS N 2006 - 035, 2006. 


\section{Tables and Figures}

Table 1: Total and average number of physicians per municipality in Belgium, according to physician type for the sampled markets (nobs $=576$ )

\begin{tabular}{|c|c|c|c|}
\hline Physician type & $\begin{array}{l}\text { Total number } \\
\text { of physicians }\end{array}$ & $\begin{array}{l}\text { Average } \\
\text { mean }\end{array}$ & $\begin{array}{l}\text { market } \\
\text { (s.d.) }\end{array}$ \\
\hline$\overline{G P P}$ & $\begin{array}{l}9,884 \\
\end{array}$ & $17 \overline{17.16}$ & $\overline{(16.76)}$ \\
\hline der & 776 & 1.35 & $(3.24)$ \\
\hline gyn & 1,431 & 2.48 & $(7.06)$ \\
\hline ped & 1,082 & 1.88 & $(4.99)$ \\
\hline opht & 1,052 & 1.83 & $(4.14)$ \\
\hline psych & 1,924 & 3.34 & $(9.12)$ \\
\hline TNE & 708 & 1.23 & $(3.15)$ \\
\hline phys & 846 & 1.47 & $(2.75)$ \\
\hline int & 3,814 & 6.62 & (19.77) \\
\hline sur & 2,700 & 4.69 & (12.64) \\
\hline hos & 5,936 & 10.31 & $(28.48)$ \\
\hline
\end{tabular}

Table 2: Descriptive statistics of market characteristics (nobs=576)

\begin{tabular}{|c|c|c|c|}
\hline Variable & & Mean & (s.d.) \\
\hline рор & number of inhabitants $(x 1,000)$ & 15.01 & $(13.59)$ \\
\hline dens & population density $(\mathrm{x} 1,000)$ & 0.50 & $(0.83)$ \\
\hline age0 4 & percentage under age of 5 & 0.06 & $(0.01)$ \\
\hline age $5-14$ & percentage in age category $5-14$ & 0.13 & $(0.01)$ \\
\hline age $1 \overline{5} \quad 29$ & percentage in age category $15-29$ & 0.18 & $(0.01)$ \\
\hline age $30 \_44$ & percentage in age category $30-44$ & 0.23 & $(0.01)$ \\
\hline age $45 \_59$ & percentage in age category $45-59$ & 0.20 & $(0.01)$ \\
\hline age60_75 & percentage in age category $60-75$ & 0.14 & $(0.02)$ \\
\hline age $75+$ & percentage over age of 75 & 0.07 & $(0.01)$ \\
\hline female & percentage female & 0.51 & $(0.01)$ \\
\hline foreign & percentage foreigners & 0.05 & $(0.06)$ \\
\hline income & mean income level $(x 10,000)$ & 2.51 & $(0.37)$ \\
\hline unempl & unemployment rate & 0.05 & $(0.03)$ \\
\hline beds_hosp & number of hospital beds (x100) & 1.55 & $(4.18)$ \\
\hline beds_rest & number of beds in retirement homes $(x 100)$ & 1.85 & $(2.20)$ \\
\hline Ant & province dummy for Antwerpen & 0.12 & $(0.33)$ \\
\hline Bru & region dummy for Brussels & 0.03 & $(0.16)$ \\
\hline$V l B$ & province dummy for Vlaams-Brabant & 0.11 & $(0.32)$ \\
\hline$B w a$ & province dummy for Brabant wallon & 0.05 & $(0.21)$ \\
\hline$W V l$ & province dummy for West-Vlaanderen & 0.11 & $(0.31)$ \\
\hline OVl & province dummy for Oost-Vlaanderen & 0.11 & $(0.31)$ \\
\hline $\mathrm{Hai}$ & province dummy for Hainaut & 0.12 & $(0.32)$ \\
\hline Lie & province dummy for Liege & 0.14 & $(0.35)$ \\
\hline Lim & province dummy for Limburg & 0.07 & $(0.26)$ \\
\hline Lux & province dummy for Luxembourg & 0.08 & $(0.27)$ \\
\hline Nam & province dummy for Namur & 0.06 & $(0.25)$ \\
\hline
\end{tabular}


Table 3: Estimation results on the strategic interaction effects of the empirical model with seven types: GPs, dermatologists (der), gynecologists (gen), pediatricians (ped), ophthalmologists (opht), class-2 specialists (class2) and class-3 specialists (class3)*

\begin{tabular}{|c|c|c|c|c|c|c|c|}
\hline & GP & der & gyn & ped & opht & class 2 & class3 \\
\hline N_GP & $\begin{array}{r}-\mathbf{1 . 2 5 2} \\
(0.13)\end{array}$ & $\begin{array}{l}\mathbf{0 . 0 4 2} \\
(0.01)\end{array}$ & $\begin{array}{l}\mathbf{0 . 0 4 8} \\
(0.01)\end{array}$ & $\begin{array}{l}\mathbf{0 . 0 6 8} \\
(0.02)\end{array}$ & $\begin{array}{l}\mathbf{0 . 0 8 3} \\
(0.02)\end{array}$ & $\begin{array}{l}0.047 \\
(0.02)\end{array}$ & $\begin{array}{l}0.055 \\
(0.05)\end{array}$ \\
\hline$N_{-}$der & $\begin{array}{r}-68.185 \\
(39.04)\end{array}$ & $\begin{array}{r}-\mathbf{0 . 9 8 2} \\
(0.06)\end{array}$ & - & - & - & - & - \\
\hline N_gyn & $\begin{array}{r}\mathbf{5 7 . 9 2 8} \\
(21.05)\end{array}$ & - & $\begin{array}{r}-\mathbf{0 . 5 8 0} \\
(0.03)\end{array}$ & - & - & - & - \\
\hline N_ped & $\begin{array}{r}-40.435 \\
(21.10)\end{array}$ & - & - & $\begin{array}{r}-\mathbf{0 . 7 5 9} \\
(0.04)\end{array}$ & - & - & - \\
\hline N_opht & $\begin{array}{r}\mathbf{3 1 . 6 1 7} \\
(16.64)\end{array}$ & - & - & - & $\begin{array}{r}-\mathbf{0 . 9 0 4} \\
(0.06)\end{array}$ & - & - \\
\hline $\mathrm{N}_{\text {_class }} 2$ & $\begin{array}{r}-\mathbf{5 . 7 8 7} \\
(1.85)\end{array}$ & - & - & - & - & $\begin{array}{r}-\mathbf{0 . 5 4 1} \\
(0.03)\end{array}$ & - \\
\hline $\mathrm{N}_{\text {_class } 3}$ & $\begin{array}{r}-0.054 \\
(0.10)\end{array}$ & - & - & - & - & - & $\begin{array}{r}-\mathbf{0 . 2 6 5} \\
(0.01) \\
\end{array}$ \\
\hline
\end{tabular}

* Each column gives the estimated coefficients of the effect of the number of physicians of the different types (rows) on the payoffs of a physician type. Standard errors are reported within brackets. Class 2 groups all psychiatrists, TNE-specialists and physiologists together, while class 3 groups internists, surgeons and hospital specialists. The associated estimated coefficients for the market controls are presented in Table 5. 
Table 4: Estimation results on the strategic interaction effects of the empirical model with six types: GPs, psychiatrists (psych), throat-, nose- and ear specialists (TNE), physiologists (phys), class-1 specialists (class1) and class-3 specialists (class 3$)^{*}$

\begin{tabular}{l|rrrrrr}
\multicolumn{1}{c}{} & \multicolumn{1}{l}{ GP } & psych & TNE & phys & class1 & class3 \\
\hline \multirow{2}{*}{ N_GP } & $-\mathbf{0 . 9 3 3}$ & $\mathbf{0 . 0 6 7}$ & $\mathbf{0 . 0 8 1}$ & 0.039 & 0.013 & 0.074 \\
& $(0.07)$ & $(0.03)$ & $(0.02)$ & $(0.03)$ & $(0.04)$ & $(0.05)$ \\
N_phys & -0.148 & $-\mathbf{0 . 5 7 5}$ & - & - & - & - \\
& $(0.65)$ & $(0.03)$ & & & & \\
N_TNE & $\mathbf{4 . 4 3 7}$ & - & $-\mathbf{0 . 8 4 1}$ & - & - & - \\
& $(1.32)$ & & $(0.06)$ & & & \\
N_phys & -0.600 & - & - & $-\mathbf{0 . 9 8 6}$ & - & - \\
& $(0.90)$ & & & $(0.06)$ & & \\
N_class1 & $-\mathbf{1 . 0 5 6}$ & - & - & - & $-\mathbf{0 . 4 3 0}$ & - \\
& $(0.39)$ & & & & $(0.03)$ & \\
N_class3 & 0.152 & - & - & - & - & $-\mathbf{0 . 2 6 3}$ \\
& $(0.07)$ & & & & & $(0.02)$ \\
\hline \hline
\end{tabular}

* Each column gives the estimated coefficients of the effect of the number of physicians of the different types (rows) on the payoffs of a physician type. Standard errors are reported within brackets. Class 1 groups all dermatologists, gynecologists, pediatricians and ophthalmologists together, while class 3 groups internists, surgeons and hospital specialists. The associated estimated coefficients for the market controls are presented in Table 6 . 


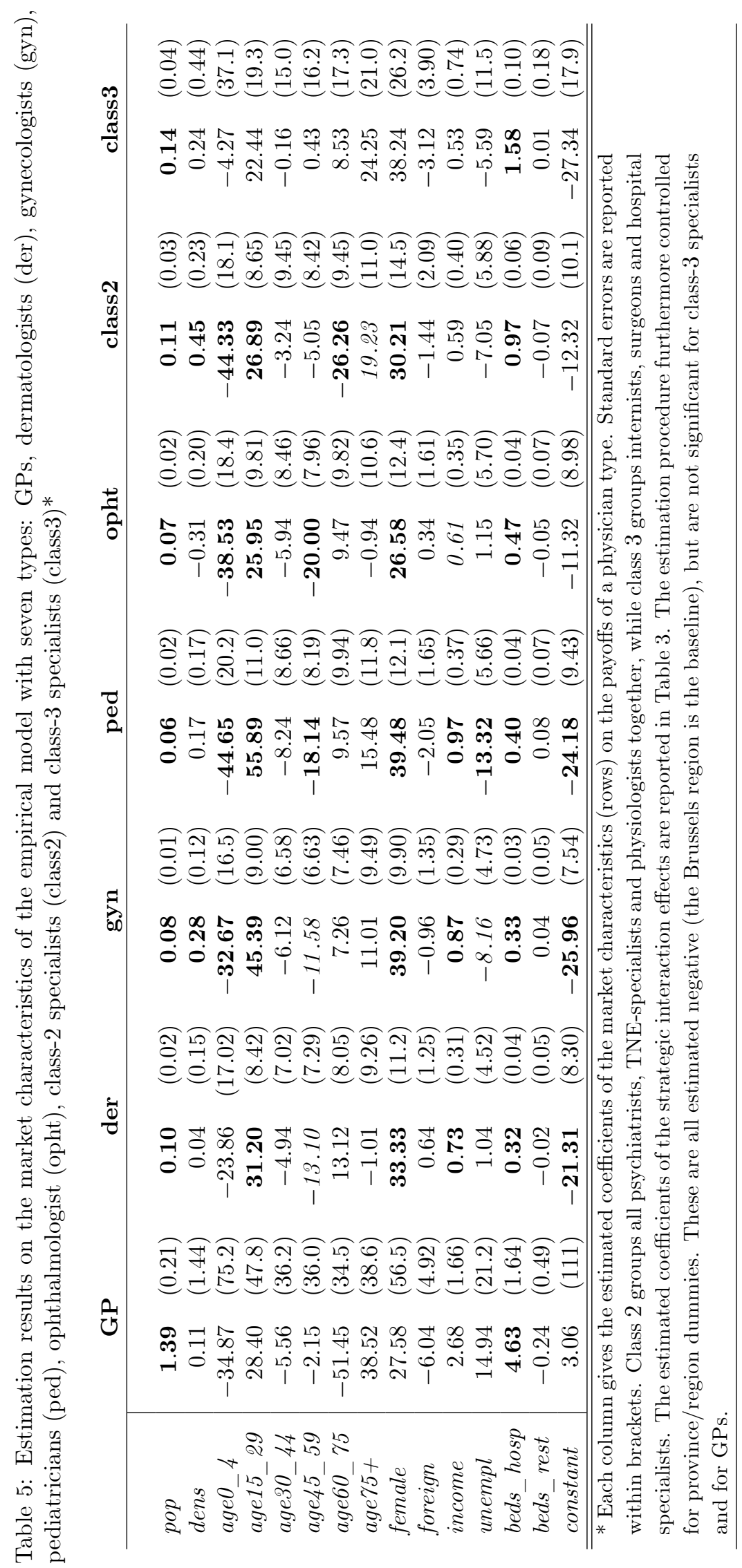




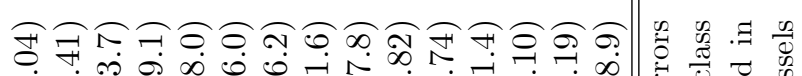

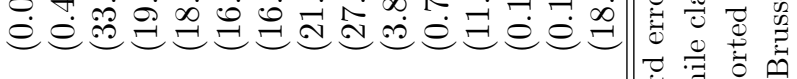

0
$\frac{0}{0}$
$\frac{\pi}{0}$

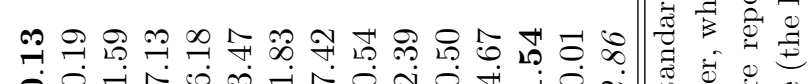

ક્0

○一

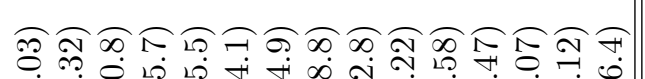

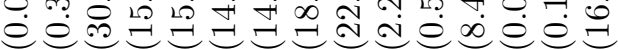

ton

옹 ㅇำ

สิ่

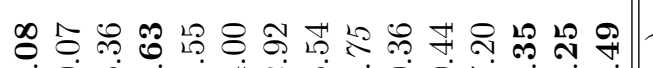

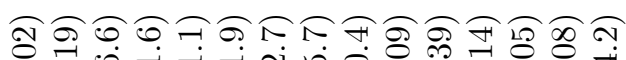

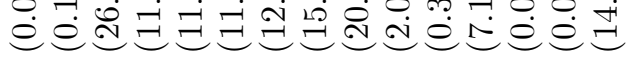

เค

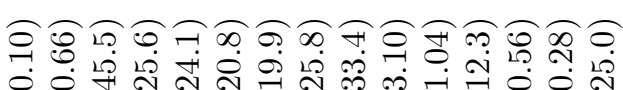

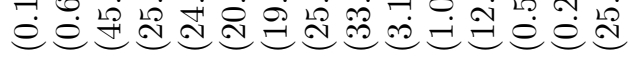

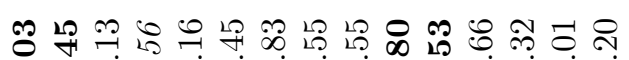
- 
Figure 1: Empirical entry game under complete information and simultaneous decision making (2 firms). Panel A represents the mapping in case payoffs of both firms are decreasing in the presence of the other firm (strategic substitutes), panel B assumes strategic complementarity in the entry decisions for both firms and panel C represents the case with asymmetric strategic interaction effects (in sign): the decision of firm 2 is a strategic substitute for the decision of firm 1, while firm 1's decision is a strategic complement to the decision of firm 2.
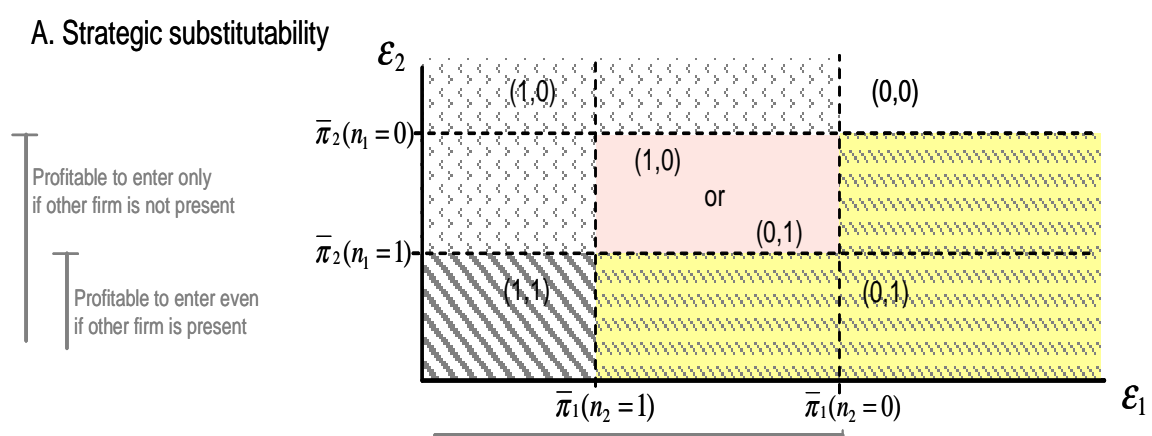

Profitable to enter if other firm is not present

Profitable to enter even if other firm is present
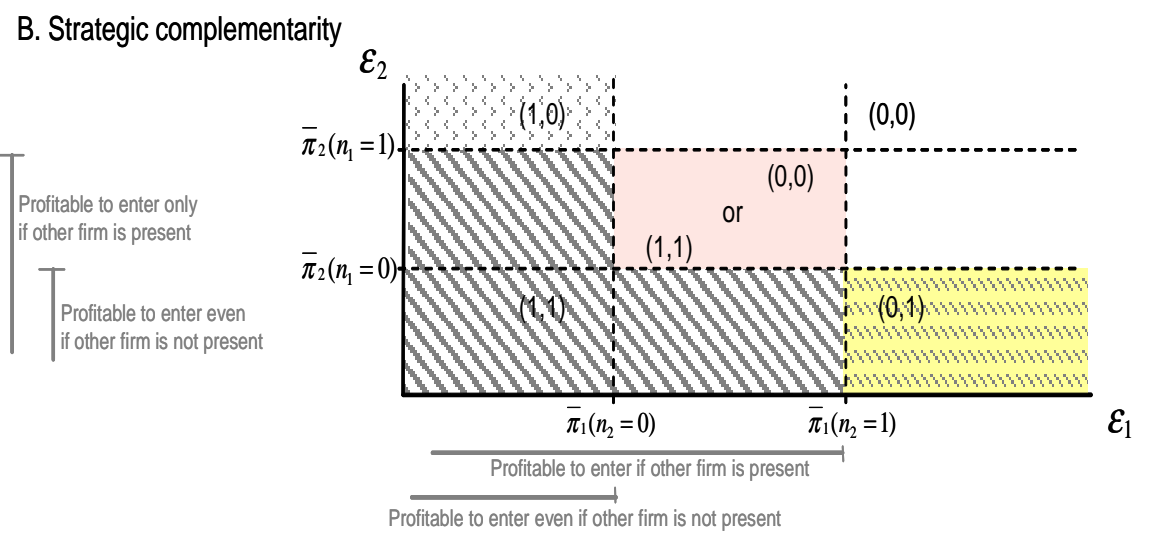

\section{Asymmetric strategic interaction effects}

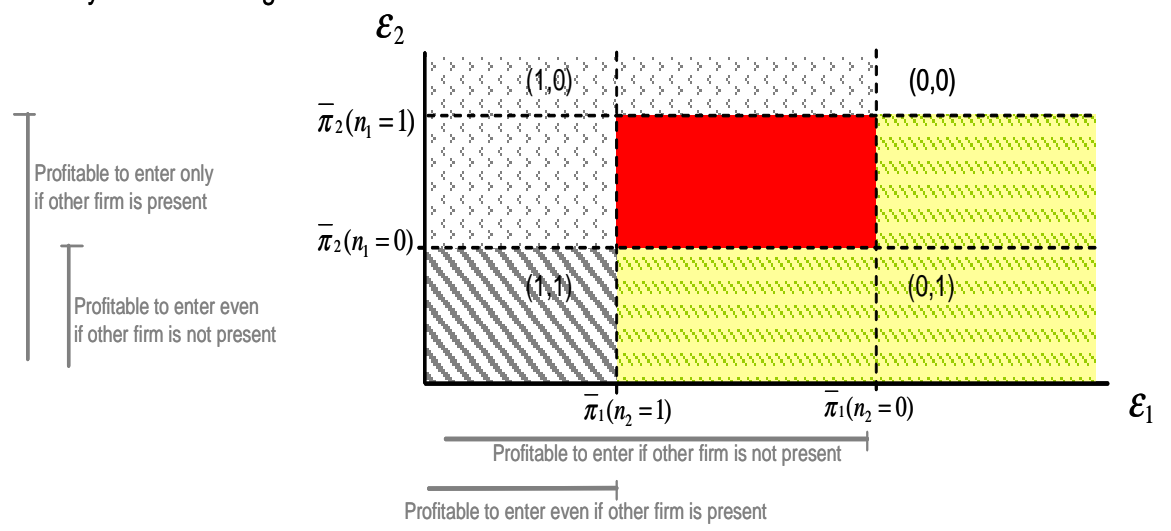


Figure 2: Empirical entry game under incomplete information and simultaneous decision making (2 firms)

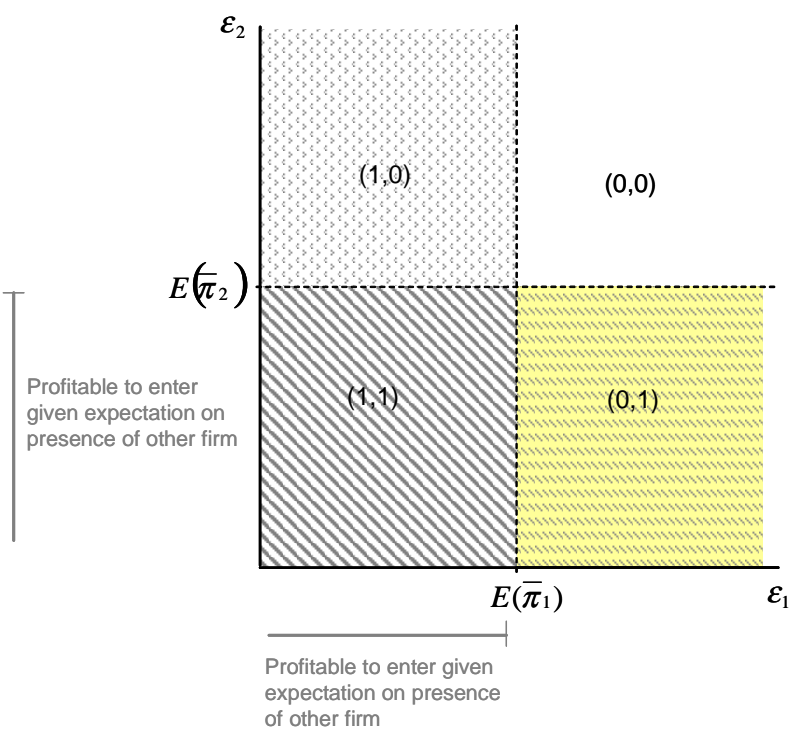

Figure 3: Empirical entry game under incomplete information and sequential decision making (firm 1 decides first).

Panel A represents the mapping when the entry decision of firm 1 is a strategic substitute in the entry decision of firm 2 , whereas panel B assumes payoffs of entry for firm 2 are increasing in the presence of firm 1 (strategic complement).

Panel A

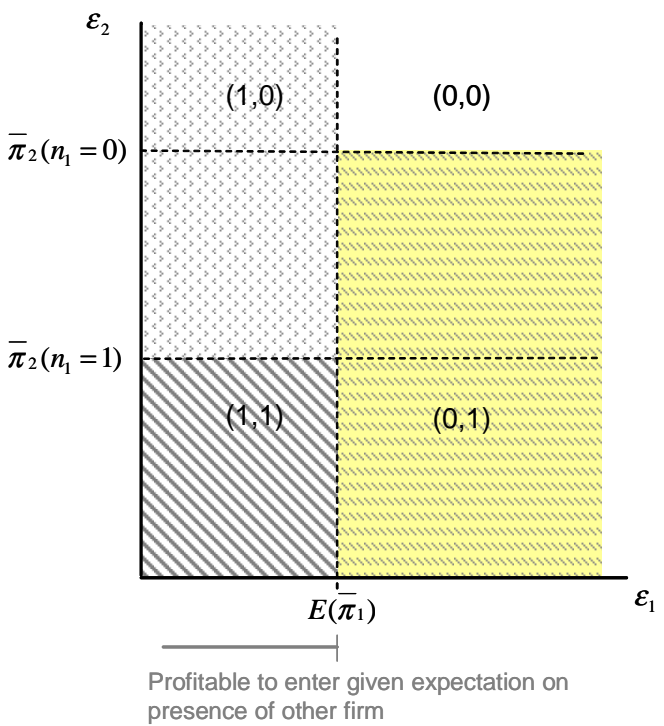

Panel B

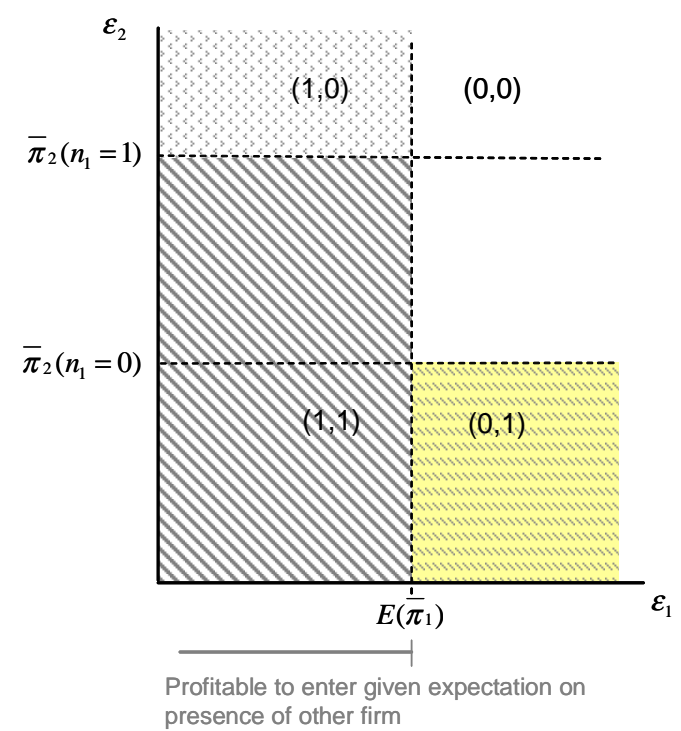

